\title{
Análisis de residuos químicos en materiales arqueológicos: marcadores de actividades antrópicas en el pasado
}

\author{
Chemical residues analysis in archaeological materials: \\ human activity markers of the past
}

\author{
Alessandra Pecci \\ Universitat de Barcelona. Departament d'Història i Arqueologia. Secció de Prehistòria i Arqueologia. \\ Institut d'Arqueologia de la Universitat de Barcelona. Equip de Recerca Arqueològica \\ i Arqueomètrica de la Universitat de Barcelona (ERAAUB) \\ C/ Montalegre, 6, E-08001 Barcelona \\ alessandrapecci@ub.edu
}

La alimentación es una cuestión clave de la investigación reciente. El desarrollo de análisis de residuos químicos en materiales arqueológicos, como cerámicas, pavimentos y depósitos de instalaciones productivas, permite obtener datos fundamentales sobre la producción y el consumo de alimentos. En este texto se discuten la potencialidad y las limitaciones de las técnicas más utilizadas y se ofrece un panorama de los resultados obtenidos en diferentes casos de estudio en yacimientos de época romana y de la Antigüedad tardía del Mediterráneo occidental, con algunos ejemplos adicionales de periodos más antiguos y recientes de las penínsulas itálica e hispánica.

\section{PALABRAS CLAVE}

ANÁLISIS DE RESIDUOS EN ARQUEOLOGÍA, ALIMENTACIÓN, PRODUCCIÓN, CONSUMO, CERÁMICAS, PAVIMENTOS, DEPÓSITOS

Alimentation is a key current research question. The development of chemical residue analyses of archaeological materials such as ceramics, floors, and vats of production installations can provide essential data on the production and consumption of foodstuffs. In this paper, the potential as well as limitations of the most common techniques of this science will be discussed and an overview of the results so far obtained in different case studies at Roman and Late Antique sites of the western Mediterranean will be presented, with reference also to earlier and later periods in the case of the Italian and Iberian peninsulas.

\section{KEYWORDS}

RESIDUES ANALYSIS IN ARCHAEOLOGY, FOOD PRACTICES, CERAMICS, FLOORS, VATS 


\section{Introducción}

El análisis de residuos químicos en materiales arqueológicos es una disciplina en auge. Según los países y las líneas de aplicación se considera a veces parte de la bioarqueología, en tanto que hablamos principalmente de análisis de residuos orgánicos (organic residue analysis, ORA) de materiales biológicos (productos de plantas y animales), o bien de la arqueometría, en cuanto trata la aplicación de técnicas de análisis instrumentales a materiales arqueológicos, y tal vez de la geoarqueología, de forma especial cuando se estudian superficies de ocupación humana, sean pavimentos o suelos de tierra batida, donde se han realizado actividades humanas, o simplemente el terreno superficial de yacimientos arqueológicos como herramienta de prospección. En este último caso, ya no se estudian solo residuos orgánicos (como ácidos grasos derivados del uso de sustancias orgánicas), sino también residuos inorgánicos, como por ejemplo las concentraciones de arsénico producidas por la extracción/producción/trabajo de metales, o de fósforo, por ejemplo, por el uso de un espacio como lugar de estabulación. Tales investigaciones pueden realizarse durante la excavación o como método de prospección arqueológica.

En este trabajo se utiliza el término "residuos químicos» y no "residuos orgánicos» (organic residue analyses, ORA), cuyo uso es el tradicional en los análisis de residuos en cerámicas, dado que los residuos no son solo de naturaleza orgánica. De hecho, Barba y su equipo siempre se refieren a residuos químicos (Barba, 2007). Esto es evidente, principalmente en el estudio de pavimentos, en los que se pueden estudiar concentraciones de elementos químicos como hierro, calcio o fósforo (Middleton, 2004), pero también en el caso de las cerámicas, que pueden haber preservado los residuos de una actividad relacionada con el trabajo de metales, o en las que es posible identificar azufre aún usando una técnica de análisis típica de los análisis de residuos orgánicos, como la cromatografía de gases acoplada a espectrometría de masas (GC-MS).

A continuación, presentamos algunos aspectos del análisis de residuos en arqueología, haciendo hincapié en aquellos relacionados con la alimentación, hecho fundamental de la vida humana: «somos lo que comemos». Para ello los resultados de los análsisi tienen que imbricarse en una investigación interdisciplinar (Besherer y Beaudry, 2015). El análisis de residuos es posible porque los materiales porosos absorben (o "adsorben", como se utiliza en términos químicos) las sustancias líquidas y semilíquidas con las que entran en contacto y las preservan. Esto es cierto para las cerámicas, como afirmaron, entre otros, Condamin y Formenti en la década de 1970 (Condamin et al., 1976) y como han demostrado sucesivamente numerosos autores. Entre ellos Richard Evershed, profesor de la Universidad de Bristol, a quien debemos la integración sistemática de esta disciplina en la arqueología (Evershed, 1993, 2008). La propiedad de los materiales de preservar los residuos, permite detectar las sustancias con las que el recipiente entró en contacto y, por lo tanto, conocer su contenido y su recubrimiento orgánico, si existió. También es posible estudiar los pavimentos (incluidos los de tierra): los líquidos empleados o producidos por las diferentes actividades humanas al caer sobre el pavimento son absorbidos por las superficies sobre las 
que se depositan y, así, son preservados (Barba, 1986, 2007; Barba y Bello, 1978). Debido a que las sustancias derramadas se mantienen en el lugar original donde las actividades humanas se llevaron a cabo y los residuos permanecen in situ, estos pueden ser considerados un marcador fiable para el estudio de la distribución espacial de las actividades, así como buenos indicadores de la función de los espacios (Barba, 1986, 2007; Barba et al., 2014; Dahlin et al., 2010; Middleton, 2004; Middleton y Price, 1996; Pecci, 2009b, 2013; Rondelli et al., 2014; Wells et al., 2000, 2017; por citar algunos ejemplos). Asimismo, es importante estudiar elementos característicos de las instalaciones productivas, como las bases de las prensas y los depósitos (Pecci et al. 2013a, 2013b, 2013c).

Los residuos químicos pueden ser considerados «marcadores de actividades antrópicas" (anthropic activity markers, AAM) (Lancelotti et al., 2017; Pecci et al., 2017a; Rondelli et al., 2014). Este término nace de la idea de que el uso duradero del espacio produce patrones distintivos de enriquecimiento y/o ausencia de productos y compuestos químicos y/o elementos físicos, que representan el resultado de la actividad que los produjo (Barba, 1986, 2007; Manzanilla y Barba, 1990; Middleton y Price, 1996; Ortiz y Barba, 1993; Ortiz et al., 2018). Rondelli y otros autores (2014) han formalizado este concepto, enraizándolo en la interdisciplinariedad, cuantificación y modelización (Lancelotti et al., 2017). Nuestro punto de vista es que no solo los residuos en pavimentos pueden ser considerados marcadores de actividades antrópicas, sino también los residuos preservados en otros espacios y materiales, como las cerámicas, y los depósitos de las instalaciones productivas.

Hasta ahora se ha utilizado el estudio de residuos en cerámicas para abordar diferentes temas relacionados con la alimentación, como el procesamiento de carnes, la introducción de ciertos alimentos en la dieta humana, la manipulación de productos lácteos y, en algunos casos, la domesticación de animales, el aprovechamiento de productos marinos, aceites vegetales, ceras y resinas, y la producción de bebidas alcohólicas, así como el uso y la función de estas. Las publicaciones sobre estos temas son abundantes (solo por mencionar algunas: Charters et al., 1993, 1997; Copley et al., 2003, 2005; Craig et al., 2007; Dudd y Evershed, 1998; Dunne et al., 2020; Evershed et al., 1997, 2003, 2008; Garnier y Valamoti, 2016; Hansel y Evershed, 2009; Hansel et al., 2004; McGovern et al., 2017; Mills y White, 1987; Pecci, 2009a; Pecci et al., 2013c, 2020; Reber et al., 2004; Regert et al., 2001; Roffet-Salque et al., 2017; Salvini et al., 2008; Stern et al., 2003). Sin embargo, pensamos que el análisis de residuos de diferentes materiales arqueológicos ofrece también un gran potencial para abordar el estudio de todo el ciclo de vida de los alimentos y las fases que lo componen, a saber: a) producción; b) conservación, almacenamiento y transporte; c) preparación (preparación en sí y cocción de los alimentos); d) consumo, y e) desecho.

Gracias al estudio de los residuos en materiales arqueológicos es posible - a pesar de muchas limitaciones- contribuir a la «arqueología del gusto» (Alexandre-Bidon, 2005) y, en ocasiones, llegar a conocer algunos aspectos de la gastronomía del pasado, entendida como «el conocimiento razonado de todo lo que relaciona al hombre mientras se nutre» (Brillat-Savarin, 1869). 
En todos los casos anteriores es necesario integrar los resultados de los análisis químicos con el resto de análisis y con el fin de conocer todas las características de los materiales examinados: la forma, la tecnología de fabricación, las huellas de uso, los desgastes y las fracturas (Alexandre-Bidon, 2005).

También es necesario incorporar los datos obtenidos con los que proporcionan el análisis botánico y el arqueozoológico.

En este artículo, nos centramos en presentar la potencialidad de los análisis de residuos para estudiar el ciclo de vida de los alimentos en diferentes épocas, incidiendo en ejemplos de época romana, tardoantigua y medieval.

\section{Metodología}

A nivel práctico, el tipo de muestreo —incluido el número de muestras a analizar- y el análisis se adaptarán al material estudiado y — desgraciadamente- al presupuesto del proyecto arqueológico en el marco en el que se realizan los análisis, en un difícil equilibrio entre la información que se puede recuperar con los diferentes análisis y el esfuerzo en tiempo y recursos que es posible invertir en los mismos. Este hecho ha limitado, en muchas ocasiones, la posibilidad de realizar proyectos a gran escala, especialmente en la cuenca mediterránea.

Consideramos que es fundamental integrar las que han sido las dos vertientes tradicionales del análisis de residuos: por un lado, el análisis de pavimentos, desarrollado principalmente en México y luego en EE. UU., y aplicado hoy en día en muchos yacimientos arqueológicos para identificar la presencia de áreas de actividad y el uso del espacio (Barba, 1986, 2007; Dahlin et al., 2010; Middleton, 2004; Middleton y Price, 1996; Ortiz y Barba, 1993; Ortiz et al., 2018; Wells et al., 2000, 2017); y, por el otro, el análisis de la cerámica, gestado en Francia, impulsado en Inglaterra y aplicado, hoy en día, en muchos laboratorios de todo el mundo (Condamin et al., 1976; Evershed, 1993, 2008). Complementaremos esta aproximación con el estudio de los elementos que constituyen las estructuras productivas, aplicado sobre todo en el sur de Europa (Pecci, 2007; Pecci et al., 2013a, 2013b, 2013c).

Debido a las diferencias en el muestreo y técnicas de análisis a emplear, tratamos por separado la metodología de estudio de los diversos materiales.

\subsection{El estudio de los pavimentos}

Como se ha indicado con anterioridad, la metodología de estudio de pavimentos incluye una primera fase de muestreo, una segunda de análisis de las muestras y una tercera de interpretación de los resultados. Como en todos los análisis espaciales, el muestreo y la definición del espacio a investigar constituyen una fase fundamental del análisis. Es 
necesario cubrir con un muestreo sistemático todo el espacio a estudiar: el análisis de una sola muestra tomada de la superficie del pavimento no puede dar información sobre el tipo de actividad realizada, a menos que esté dirigido a responder una pregunta específica. Además, el espacio debe ser suficientemente grande para permitir identificar un patrón en la distribución espacial de los residuos. Por eso, el análisis químico de los pavimentos tiene su máxima potencialidad en el caso de una excavación extensiva y estratigráfica. Muestrear la totalidad de la superficie de un edificio para comprenderlo en su totalidad es lo óptimo. Los estudios realizados en Teotihuacan, México, donde se han muestreado grandes complejos son, en este sentido, ejemplares (Ortiz y Barba, 1993; Ortiz et al., 2018). No obstante, es también posible investigar espacios más pequeños como cocinas o cabañas (Pecci 2009b, 2013).

El número de muestras a seleccionar y su distribución en el espacio varían en función del tipo de contexto arqueológico. La experiencia acumulada permite sugerir que la distancia de un metro o $50 \mathrm{~cm}$ entre las muestras es apropiada si se trabaja en el interior de estructuras, mientras que, en espacios exteriores, el espaciado - la malla- que se utiliza es mayor (Barba, 2007; López Varela et al., 2006; Middleton et al., 2010). Tanto en un caso como en el otro el número de muestras resulta muy elevado. Por esta razón, normalmente, se prefiere aplicar para su análisis técnicas rápidas, como pueden ser los spot tests semicuantitativos siguiendo la metodología publicada por Barba y otros autores (1991) y afinada por Barba (2007), para determinar la presencia de fosfatos, ácidos grasos, residuos proteicos, carbonatos, carbohidratos y el nivel de $\mathrm{pH}$. Estas pruebas no permiten identificar con precisión las sustancias químicas presentes (i.e., determinar si las grasas son de origen animal o vegetal) o su cantidad. Sin embargo, tienen la ventaja de poder procesar grandes cantidades de muestras de forma rápida y económica, y apreciar así patrones de enriquecimiento químico e identificar áreas de actividad, incluidas las relacionadas con la preparación y el consumo de alimentos (Barba et al., 2014). Además, pueden servir para seleccionar las muestras susceptibles de ser analizadas con técnicas más especializadas, como la cromatografía de gases acoplada a espectrometría de masas (GC-MS), con el fin de obtener información más detallada sobre las actividades realizadas. Con estos análisis es posible identificar, por ejemplo, si la fuente de grasa absorbida por un pavimento es animal o vegetal y/o averiguar si en una habitación fue almacenado queso o aceite.

Para el estudio de pavimentos también se puede usar la espectrometría de masas con plasma acoplado inductivamente (ICP-MS), o la fluorescencia de rayos X (XRF), en busca de elementos químicos que puedan estar relacionados con la realización de actividades específicas (ej. Dahlin et al., 2010; Middleton, 2004; Wells et al., 2000, 2017). En estos casos no hay que olvidar que estas técnicas no identifican residuos orgánicos generados por las diferentes actividades, sino elementos químicos que pueden estar relacionados con ellas, y que los resultados son susceptibles de estar influidos por el substrato del terreno y, por lo tanto, hay que ser muy prudentes con las interpretaciones que se propongan. Esto es particularmente importante cuando la toma de muestra se hace in situ con XRF portátil. La búsqueda de patrones de enriquecimiento a nivel etnoarqueológico y su modelización 
pueden ser útiles para minimizar estos problemas (Fernández et al., 2002; Knudson y Frink, 2010; Lancelotti et al., 2017; Middleton, 2004).

Un ejemplo extremadamente significativo de la aplicación de estas técnicas es el hallazgo de áreas de producción de metales (Cook et al., 2003, 2005).

Una vez realizados los análisis, los resultados se vuelcan en una base de datos espaciales implementada en un SIG (sistema de información geográfica) y se interpolan para obtener mapas de distribución espacial de los residuos, utilizando diferentes software y técnicas de interpolación. La finalidad de este proceso es identificar áreas de concentración y ausencia de residuos relacionadas con áreas de actividad. Por esta razón, los mapas de distribución deben ser interpretados a la luz del contexto estudiado.

Para poder considerar las concentraciones y ausencias de residuos como marcadores de actividades, es necesario que la composición original de las superficies estudiadas sea homogénea. De otra forma, las divergencias pueden deberse a diferencias en la composición química del pavimento. Un ejemplo de ello son los resultados obtenidos al estudiar la cocina de la Bottega del Garum de Pompeya. Aquí el pavimento presenta valores mayores de fosfatos respecto a la superficie del horno, porque el pavimento estaba hecho de tierra mezclada con cal, mientras la superficie del horno era de argamasa (Pecci et al., 2018) (fig. 1).

Los materiales idóneos para realizar este tipo de estudio son las baldosas o ladrillos empleados para la construcción de pavimentos: se trata de un material cerámico que goza de las mismas propiedades de absorción que los recipientes (fig. 1). Sin embargo, hasta ahora son pocos los casos en los que se han practicado (Pecci, 2004). También se pueden analizar pavimentos manufacturados con argamasa o mortero, como los pavimentos de las estructuras mesoamericanas de Teotihuacan o del Templo Mayor en México y los de época romana y medieval (Barba, 1986, 2007; Barba et al., 2014; Ortiz y Barba, 1993; Ortiz et al., 2018; Pecci, 2013). Se trata de superficies químicamente «neutras» por el proceso de fabricación de la cal, que no son ricas en residuos en el momento de su fabricación. Esta característica puede ser aprovechada para analizar, además de los pavimentos, los depósitos de las estructuras productivas que eran recubiertos de argamasa o mortero y así comprender la función de las instalaciones productivas. Un caso aparte es el del opus signinum, debido a la posibilidad que se haya empleado en su fabricación cerámica previamente usada y, por lo tanto, enriquecida de residuos orgánicos. En este caso hay que separar la cerámica de la cal, y analizar solo la segunda.

Asimismo, el estudio arqueológico y etnoarqueológico de los pavimentos de tierra ha demostrado que también estos pueden ser analizados, debido a que retienen los residuos químicos (Barba y Bello, 1978; Dahlin et al., 2010; Fernández et al., 2002; López Varela et al., 2006; Middleton y Price, 1996; Oonk et al., 2009; Parnell et al., 2002; Pecci et al., 2017a, 2017b; Rondelli et al., 2014; Wells et al., 2000, entre otros). En estos casos es importante combinar el análisis químico con el microestratigráfico y posiblemente de restos microbotánicos (Rondelli et al., 2014; Shillito, 2017).

Para la interpretación de las actividades realizadas en un espacio es necesario «contextualizar» los resultados de los análisis químicos e integrarlos en un estudio interdisci- 

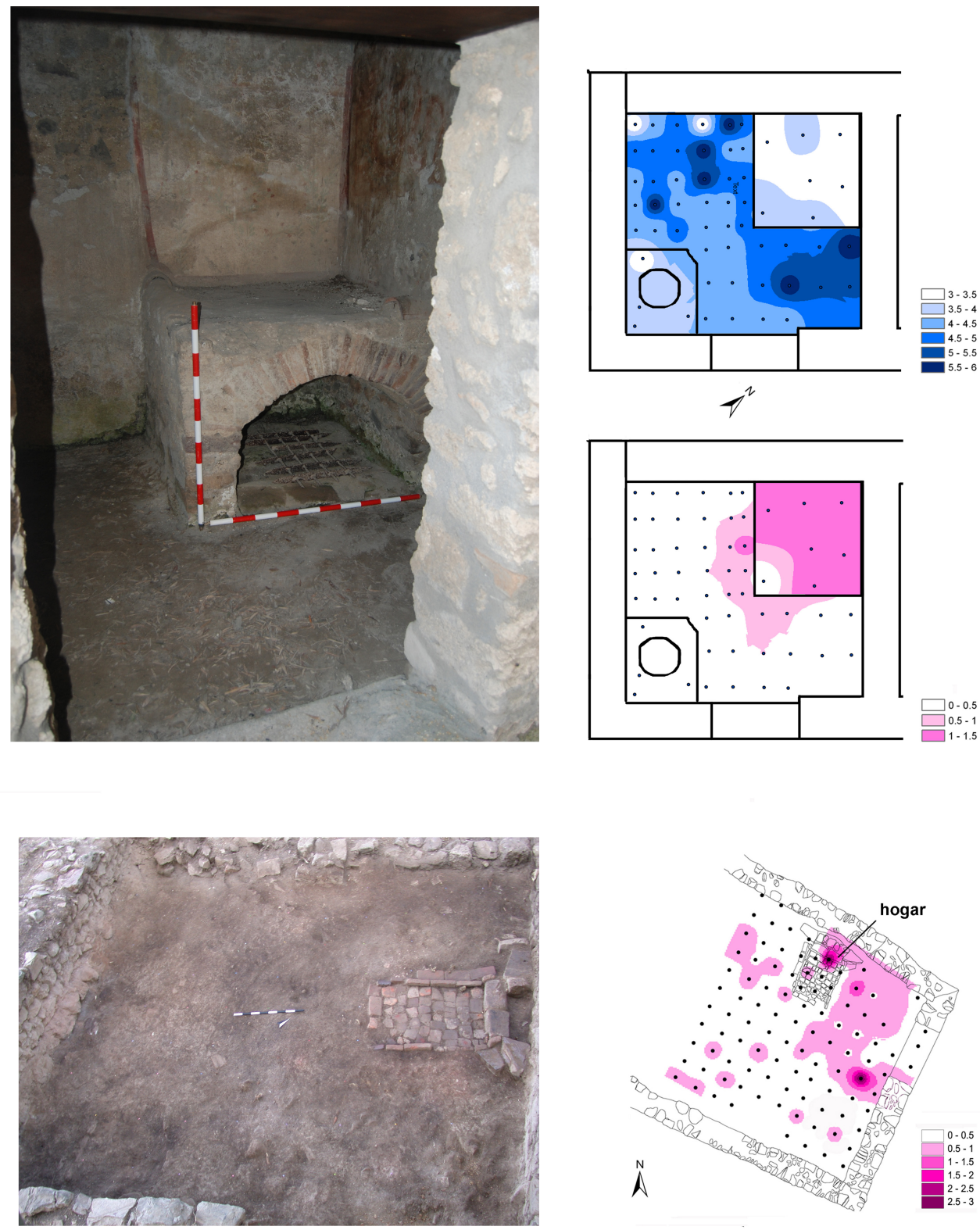

Figura 1. Arriba: cocina de la Bottega del Garum de Pompeya y mapa de distribución de fosfatos (azul) y de ácidos grasos (rosa). Abajo: fotografía de la excavación de una habitación usada como cocina en el yacimiento de Castel di Pietra y mapa de distribución de ácidos grasos. La escala de valores de fosfatos es de 0 a 6 y la de ácidos grasos de 0 a 3. Las muestras se han extraído cada $50 \mathrm{~cm}$. 
plinario que implique el análisis arqueobotánico, arqueozoológico, de la cerámica, lítico, de los metales y, en general, de todos los materiales hallados en el contexto, para obtener la mayor información posible sobre el uso del espacio. Además, es ineludible sopesar todos los elementos arquitectónicos que pueden haber influido en la distribución espacial de las actividades y, por lo tanto, en los residuos químicos depositados y absorbidos por los pavimentos.

En la interpretación es necesario considerar que los patrones de distribución de residuos químicos caracterizados por la ausencia de residuos son tan significativos como aquellos en los que destacan sus concentraciones. Este es el caso, por ejemplo, de la ausencia de residuos orgánicos que permite excluir algunas actividades como la preparación y/o el consumo de alimentos o la producción de aceite y sugerir la práctica de ciertas actividades que no dejan residuos químicos, como por ejemplo dormir (las «actividades ausentes» de Sánchez y Cañabate, 1998).

Un problema relacionado con la aplicación de este tipo de análisis deriva del hecho de que las superficies del pavimento son palimpsestos que absorben los residuos de todas las actividades llevadas a cabo sobre ellos, sin que se pueda establecer una secuencia temporal de su deposición. Esto implica que, en el caso de un uso prolongado o el cambio de uso de una habitación, no sea plausible una correcta interpretación, al igual que en áreas o espacios plurifuncionales o multifuncionales.

Si, a su vez, estudiamos las muestras solo con spot tests, la interpretación de las áreas de actividad resulta compleja dado que diversas actividades pueden comportar el depósito de residuos que no son diferenciables. En ocasiones, para resolver este problema, son aplicables técnicas de análisis más especializadas, como la GC-MS, a un número limitado de muestras, con el fin de obtener información sobre el origen de los residuos y, por lo tanto, sobre las actividades realizadas. Con estos análisis, como se verá a continuación, es posible identificar, por ejemplo, si la fuente de grasa absorbida por un pavimento es animal o vegetal y/o averiguar si en una habitación fue almacenado queso o aceite.

\subsection{El estudio de las cerámicas}

Al igual que los pavimentos, las cerámicas son un material poroso y pueden ser estudiadas para investigar qué sustancias han entrado en contacto con ellas (fig. 2). Esto permite entender cuál fue su contenido y, cuando existe, su recubrimiento orgánico. Las cerámicas idóneas para el estudio de residuos químicos son las cerámicas de cocina de granulometría gruesa (coarse), en las que además el calor facilita la absorción (Evershed, 2008), pero también pueden ser estudiadas las ánforas, la cerámica fina e, incluso, la vidriada (Frère y Garnier, 2017; Pecci et al., 2016a, 2016c; Valdambrini et al., 2006).

Si el objetivo del estudio de la cerámica es solo comprender el contenido del recipiente, como, por ejemplo, en el caso de las ánforas, será suficiente extraer una muestra del contenedor. En este caso, es fundamental extraer la muestra de un punto en el que 
Figura 2. Muestreo de cerámica para análisis de residuos.

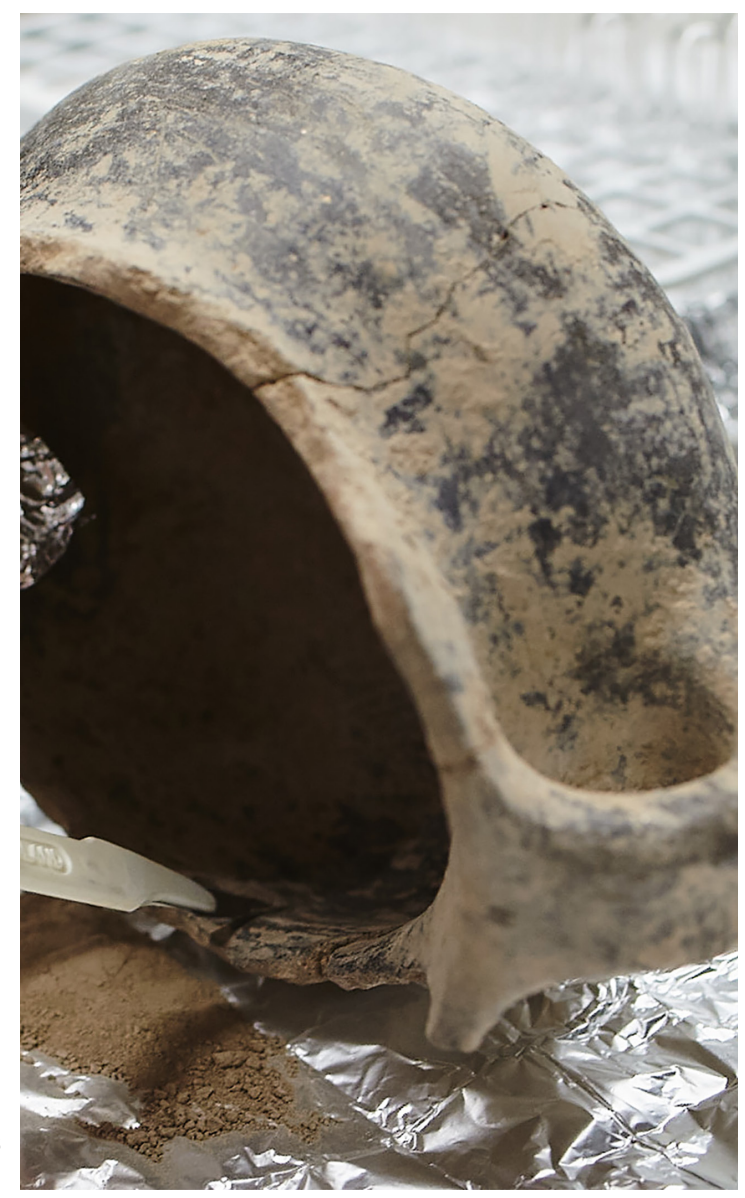

el contenedor estuviera en contacto con el contenido. En las ánforas, si extraemos una muestra del labio, solo conoceremos la sustancia usada para sellarlas y no su contenido original. En las cerámicas de cocina, dependiendo del tipo de cocción aplicada, la absorción de residuos será diferente. Por ejemplo, en las ollas, los lípidos se concentran en la parte alta de la pared, debido a que las grasas están en suspensión, mientras que, si se cocina un estofado, las grasas se acumulan mayoritariamente en el fondo (Charters et al., 1993). Lo dicho puede ayudar a acercarnos al estudio de las formas de preparar los alimentos, al método de cocción utilizado y, tal vez, facilitar la reconstrucción de las recetas. En este caso, hay que realizar un muestreo más complejo, que implica la extracción de al menos dos o tres muestras de cada contenedor en sus diferentes partes (fondo, pared, borde). Si se preservan residuos sólidos, estos deben ser muestreados, ya que representan el último uso de la cerámica. 
Para verificar que no existe contaminación posdeposicional es necesario analizar muestras de control, normalmente del sedimento de la unidad estratigráfica de la que se ha recuperado la muestra. Algunos análisis realizados por la autora de la tierra adherida a recipientes enriquecidos experimentalmente y sepultados, revelan que el suelo puede absorber residuos de la cerámica, así que la muestra de control debe ser recuperada a algunos centímetros de la cerámica. En general, la contaminación por parte del contexto de deposición es escasa (Heron et al., 1991; Skybo, 2013).

Para determinar los contenidos orgánicos de las cerámicas hay que identificar los que Evershed denominó biomarcadores, o sea, las "huellas digitales» (fingerprints) químicas "típicas de compuestos y mezclas que existen en sustancias que tienen la posibilidad de haber sido usadas en el pasado" (Evershed, 1993, 2008). Identificar los biomarcadores de las sustancias no es una cuestión fácil dado que las sustancias se degradan por transformaciones que dependen de factores humanos, las c-transform de Schiffer (1992), como la fabricación y el uso del material (por ejemplo, por la cocción de los alimentos o el proceso de fabricación de la pez/brea), así como por procesos posdeposicionales, que en muchos casos están relacionados con factores naturales que dependen del contexto de deposición, las n-transform de Schiffer (1992). Por esta razón, hay que llevar a cabo trabajos experimentales y etnoarqueológicos que permitan reconocer los biomarcadores químicos de las diferentes sustancias (Barba et al., 2014; Charters et al., 1993; Correa-Ascencio y Evershed, 2014; Dunne et al., 2019; Evershed, 2008; Garnier y Valamoti, 2016; Pecci et al. 2013c; Roffet-Salque et al., 2017; Romanus et al., 2009; Skybo, 2013).

La técnica que hasta ahora ha permitido alcanzar los mejores resultados para identificar con precisión los residuos preservados en los materiales arqueológicos es la cromatografía de gases acoplada a espectrometría de masas (GC-MS). No obstante, se pueden aplicar otras técnicas de análisis como la cromatografía líquida, la pirólisis y, en ocasiones, la espectroscopía de transmisión de infrarrojo puede brindar informaciones importantes. Además, hay que aplicar diferentes técnicas de extracción adaptadas a los residuos objeto de estudio (lípidos, vino...). La extracción más común es la que permite obtener el llamado «extracto lipídico total» (total lipid extract, TLE) (Charters et al., 1993; Mottram et al., 1999); más recientemente se ha empezado a usar para este fin la "extracción ácida», desarrollada por Correa-Ascencio y Evershed (2014). Para la identificación de residuos de vino existen diferentes extracciones (Garnier y Valamoti, 2016; Guasch-Jané et al., 2004; McGovern et al., 2017; Pecci et al., 2013c, 2020).

La interpretación de los contenidos de las cerámicas puede afinarse realizando análisis isotópicos de los ácidos grasos libres obtenidos con la extracción para el extracto lipídico total (gas chromatography - combustion - isotope ratio mass spectrometry, GC-C-IRMS). La aplicación de esta técnica tiene una larga tradición en Inglaterra (Charters et al., 1993; Craig et al., 2007; Evershed, 2008; Dunne et al., 2012, 2019; Evershed et al., 2008; Regert, 2011 ; Roffet-Salque et al. 2017) y permite, teniendo en cuenta también la presencia de biomarcadores específicos, diferenciar entre grasas del tejido adiposo o de productos lácteos, productos marinos o de agua dulce y otros productos de origen animal. 
Como mencionamos al inicio, el estudio de los contenidos de las cerámicas ha permitido identificar las grasas animales procesadas/conservadas en los recipientes, la presencia de aceites vegetales - en ocasiones diferentes del de oliva (p. ej., de ricino o de moringa)-, de mijo, maíz, cacao, jugo de agave, ceras vegetales, así como de sustancias usadas para recubrir los recipientes o utilizadas con fines no alimenticios, como cera de abeja, resinas, pez o incienso (Charters et al., 1993, 1997; Colombini et al., 2005; Copley et al., 2003, 2005; Correa-Ascencio y Evershed, 2014; Craig et al., 2007; Dudd y Evershed, 1998; Dunne et al., 2012, 2019; Evershed, 1993, 2008; Evershed et al., 2008; Garnier, 2015; Garnier et al., 2009, 2011; Hansel y Evershed, 2009; Heron et al., 2016; Mills y White, 1987; Pecci, 2009a; Pecci et al., 2010, 2013c; Reber et al., 2004; Regert, 2011 ; Regert et al., 2001; Roffet-Salque et al., 2015; Stern et al., 2003, entre otros).

En cuanto al vino, el ácido tartárico es considerado su biomarcador (Barnard et al., 2011; Garnier y Valamoti, 2016; Guasch-Jané et al., 2004; McGovern, 2004; Pecci et al., 2013c, 2020), dado que este ácido, aun encontrándose también en otras frutas, es muy abundante en la uva y, por lo tanto, su presencia generalmente indica que el zumo de la uva/vino o derivados estuvieron en contacto con los materiales arqueológicos en los que se identifica. Debido a que el ácido tartárico se encuentra también en otros frutos como el tamarindo (Barnard et al., 2011) o la granada, para poder interpretar la presencia de este ácido como marcador de uva es primordial tener en cuenta el contexto históricoarqueológico y los datos botánicos del yacimiento o del área geográfica estudiada, para sugerir el consumo o la producción de vino en un lugar específico. Esto es cierto en particular cuando se propone la introducción de la producción o consumo de vino en épocas muy antiguas (ej. Edad del Bronce o Neolítico) (Garnier y Valamoti, 2016; McGovern et al., 2019; Pecci et al. 2020). Los mismos análisis permiten reconocer la presencia de otros ácidos como el succínico, málico, maleico, fumárico, cítrico, que también se encuentran en el vino, pero no pueden considerarse biomarcadores de esa sustancia. El ácido siríngico, un producto de degradación de la malvidina, es el marcador del vino tinto (Barnard et al., 2011; Guasch-Jané et al., 2004). Sin embargo, es un ácido presente también en otros materiales, incluido el corcho, y requiere prudencia al considerarlo como tal (Garnier y Valamoti, 2016). Finalmente, es importante recordar que por el momento no es posible diferenciar entre el vino y sus derivados, como el vinagre o el arrope.

Una vez analizadas las muestras, como se ha señalado con respecto al análisis de pavimentos, es necesario interpretar los resultados. También, en este caso, los datos obtenidos mediante la "aplicación de técnicas científicas» se someten a dos fases interpretativas: primero, "la interpretación científica de los datos», en el caso específico, comprender qué compuestos químicos están presentes en las muestras; y posteriormente, «la interpretación del significado arqueológico de los datos científicos», estableciendo la presencia de un determinado contenido o recubrimiento de la cerámica y su significado arqueológico e histórico (Mannoni y Giannichedda, 1996; Pecci, 2009a).

Para alcanzar el "segundo nivel interpretativo" es necesario integrar los resultados de los análisis químicos con todos los indicadores arqueológicos del uso de las cerámicas: 
el estudio completo de la cerámica y de su contexto (Skybo, 2013). Es importante considerar el tipo de pasta de la cerámica, la forma, la capacidad, la presencia de huellas de quemado, de desgaste, de roturas y reparaciones. Esto adquiere particular relevancia si se quiere comprender la posible influencia de la cerámica sobre el gusto de los alimentos (Alexandre-Bidon, 2005). También es indispensable relacionar los resultados obtenidos con el contexto arqueológico de los contenedores, desde el tipo de habitación hasta el conjunto de elementos de la cultura material hallados en el contexto, y en particular los macro y microrrestos arqueozoológicos y arqueobotánicos.

Finalmente, hay que integrar la información obtenida a partir de los análisis con los datos que recuperamos de las fuentes documentales y la iconografía, como recetarios o representaciones de banquetes o escenas de comensalía y liturgia alimentaria, relativos al periodo y lugar investigados.

La caracterización de residuos orgánicos en cerámicas también tiene sus límites. Como ya se ha indicado a propósito de los pavimentos, una de las limitaciones del análisis de residuos es el hecho de que los materiales porosos absorben las diferentes sustancias con las que entran en contacto. Esto implica que no es posible comprender si las sustancias identificadas con los análisis fueron contenidas o cocinadas por separado o mezcladas (como en el caso del oenogarum) y, debido a que los contenedores a menudo no han tenido un único uso, es complejo diferenciar los diversos tipos de productos cocinados o almacenados en momentos distintos. Además, dado que no solo se pueden identificar los residuos derivados del contenido del recipiente, sino también los del posible recubrimiento, como la impermeabilización con resina/pez, la presencia de varias sustancias puede ser interpretada de diferentes maneras. Por ejemplo, la cera de abeja asociada a la grasa animal puede derivar de la mezcla de las dos sustancias para recubrir el recipiente o de cocinar un caldo aderezado con miel. Todo lo anterior implica que a veces es necesario proponer hipótesis diversificadas sobre el contenido y el recubrimiento de las cerámicas.

Sin embargo, en ocasiones es posible acercarnos a entender las formas de preparar alimentos, en la línea de la antes mencionada «arqueología del gusto» (Alexandre-Bidon, 2005). Para ello, durante el estudio de las cerámicas es importante realizar muestreos que permitan una mejor comprensión de su contenido y su uso.

Las investigaciones recientes indican la necesidad de desarrollar un acercamiento multiproxy en el estudio de la cerámica y de otros materiales arqueológicos, y complementar el análisis de residuos con estudios microbotánicos de polen, fitolitos y almidones. En particular, el estudio de los granos de almidones posibilita la identificación del procesado de trigo, legumbres, cacao o maíz, y en ocasiones hasta evaluar las temperaturas de cocción alcanzadas (Barton y Torrence, 2015), facilitando el diagnóstico de contenidos vegetales en las cerámicas, que el análisis de residuos no permite reconocer (con pocas excepciones, Dunne et al., 2019; Ganzarolli et al., 2018; Hammann y Cramp, 2018; Heron et al., 2016).

En el caso de la preservación de un contenido sólido, será importante realizar también un examen arqueozoológico: en diferentes ocasiones el estudio de restos de pescado ha 
permitido identificar la conservación de pescado troceado, o la existencia de diferentes preparaciones a base del mismo, como diversas recetas de garum o allec (Bernal et al., 2020).

La historia de la investigación de los análisis de residuos, como ya se ha avanzado, revela la importancia de los materiales cerámicos no revestidos y posiblemente de cerámica en 'pasta gruesa' (coarse ware), como son, por regla general, las ánforas y las cerámicas de cocina. Sin embargo, es posible también el estudio de materiales cerámicos 'para la mesa'. Finalmente, se ha explorado la posibilidad de examinar recipientes de vidrio y metal, principalmente en contextos cerrados. El análisis realizado por Garnier en Lavau (Garnier y Dubuis, 2019) es, en este sentido, ejemplar.

\subsection{El análisis de las instalaciones productivas}

En el estudio de las instalaciones productivas se pueden seleccionar muestras diferentes. Generalmente, el objetivo es conocer la sustancia producida en la estructura y, para ello, es importante analizar el contenido de los depósitos, que en la mayoría de los casos es de argamasa, como veremos en los próximos párrafos. En estos casos, hay que obtener muestras de las partes de los depósitos que estuvieron en contacto con la sustancia producida (el fondo o la pared de los depósitos). También es posible muestrear los conductos que llevan a estos depósitos, o las bases de las prensas y las piedras de los molinos para confirmar su uso para moler aceitunas u otros productos (Pecci et al., 2013b). Solo recientemente se ha demostrado que se pueden estudiar también muestras de piedra, como veremos más adelante.

Asimismo, de existir, son susceptibles de análisis las cerámicas empleadas en el proceso productivo (por ejemplo, los dolia).

Si el análisis tiene como objetivo conocer la distribución espacial de las actividades realizadas, se pueden estudiar también los pavimentos de las estructuras (Pecci y D'Andria, 2014; Pecci et al., 2013b).

En cuanto al tipo de análisis a aplicar, según el material y el objetivo del estudio, se aplicará lo ya propuesto en los apartados anteriores.

\section{El ciclo de vida de los alimentos}

Como hemos anunciado, a continuación, abordamos el estudio del ciclo de vida de los alimentos a partir del análisis de residuos, es decir, las diferentes fases por las que pasa el alimento antes, durante y después de su consumo.

Los casos de estudio presentados derivan de trabajos que hemos realizado durante los últimos veinte años colaborando en diferentes proyectos y relacionados con el estudio de la alimentación en el Mediterráneo occidental. 


\subsection{Producción de alimentos: el estudio de las instalaciones productivas}

La producción de los alimentos es la primera fase de su ciclo de vida. La arqueología le ha dedicado muchos esfuerzos y ha abordado esta fase bajo diferentes puntos de vista. El análisis de residuos químicos puede ser usado en combinación con otras técnicas —en particular, micromorfología y botánica— para examinar algunos de estos aspectos, así por ejemplo el uso de estiércol como fertilizante en el cultivo o en áreas destinadas al pastoreo (Egüez et al., 2018). Sin embargo, el mayor potencial de la aplicación del análisis de residuos está relacionado con el estudio de las estructuras productivas para la obtención de sustancias líquidas, como son el vino, el aceite o los derivados del pescado.

Estas estructuras se caracterizan por la presencia de residuos químicos que dependen de la naturaleza de la sustancia producida. En el caso de los molinos para aceite, por ejemplo, el estudio etnoarqueológico pone de manifiesto que la superficie del pavimento muestra concentraciones de ácidos grasos y fosfatos detectados con spot tests. En este caso, la aplicación de GC-MS ayuda a confirmar la presencia de aceites vegetales (Pecci y D’Andria, 2014; Pecci et al., 2013b).

Las estructuras de producción de vino se caracterizan por la ausencia de grasas y la presencia de biomarcadores de la uva que, como ya se ha indicado, pueden ser identificados por cromatografía de gases o cromatografía líquida acopladas a espectrometría de masas.

Una importante aplicación del análisis de residuos es, de hecho, la que permite diferenciar las estructuras productivas destinadas a la producción de aceite y de vino (Pecci et al., 2013a). En algunas ocasiones, cuando las instalaciones son complejas y están bien preservadas, normalmente conservan elementos suficientes para que puedan ser reconocidas solo a partir de los restos arqueológicos (Brun, 1993, 2003, 2004; Peña Cervantes, 2010 , 2019). Las instalaciones para la producción de vino, por ejemplo, presentan un calcatorium, en relación con el pisado de la uva, bases de prensas y, al menos, un lacus, un depósito usado para la recolección del mosto obtenido del prensado de la uva. Asimismo, es común encontrar dolia para la fermentación del vino, en muchos casos parcialmente enterrados (dolia de fossa). Por el contrario, las instalaciones de aceite se caracterizan por la presencia de molinos para moler las aceitunas, prensas para la extracción del aceite y depósitos de recolección y decantación del líquido extraído de las aceitunas conectados entre sí por la parte superior o inferior para poder separar el aceite (Peña Cervantes, 2019).

Sin embargo, si la conservación de las estructuras productivas es parcial, no siempre es fácil diferenciar las estructuras vinarias de las olearias. En estos casos, el análisis de residuos es de especial relevancia porque, como ya se ha indicado, la argamasa, a menudo opus signinum, del revestimiento de los depósitos absorbe las sustancias líquidas con las que entra en contacto y preserva los residuos, lo que permite identificar la sustancia contenida en esos depósitos y, por lo tanto, la función de las instalaciones de producción. Este enfoque metodológico confirma la producción de vino o aceite en yacimientos arqueológicos de época romana y tardoantigua (Pecci, 2013, 2019; Pecci et al., 2013a, 2013c). 

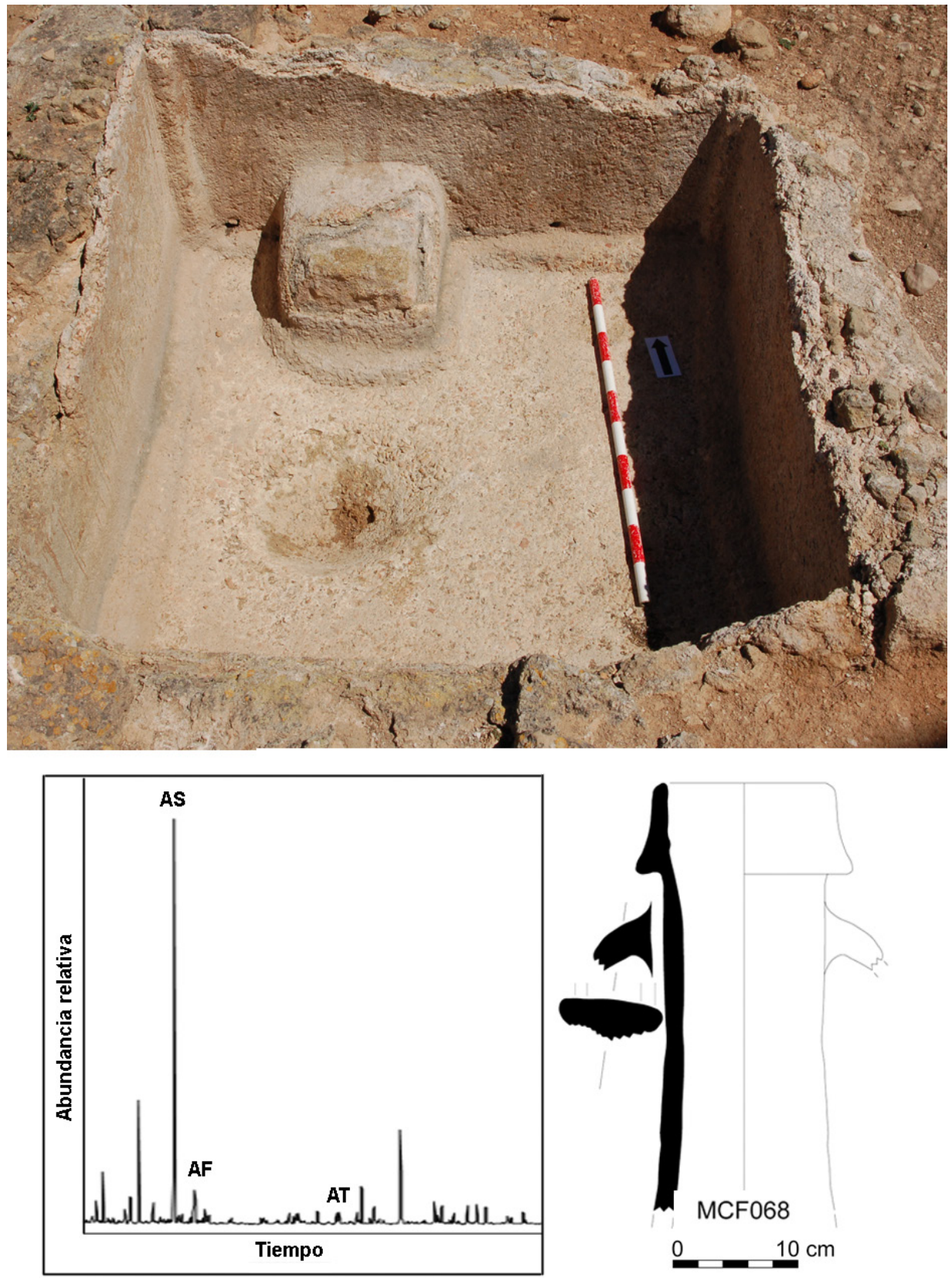

Figura 3. Depósito hallado en Sa Mesquida y cromatograma parcial donde se pueden observar los marcadores del vino (ácido succínico (AS), ácido fumárico (AF) y ácido tartárico (AT). Ánfora Dr 1b encontrada en el mismo yacimiento (modificado de Cau et al., 2018). 
Este método fue probado por primera vez en Italia, en el yacimiento de Donoratico (Toscana), en el estudio del fondo de un lacus probablemente del siglo III d. C., en el que se identificaron residuos de vino, y del fondo de un lacus del yacimiento romano hallado en el centro de la ciudad moderna de Lecce, que presentó residuos compatibles con el aceite de oliva (Pecci, 2007). Posteriormente, se analizaron dos calcatoria y un lacus de la llamada Villa de Augusto, en Somma Vesuviana (Allevato et al., 2012; Pecci et al., 2013c), y depósitos de otros yacimientos de Italia y de la península ibérica. Entre ellos, se han identificado residuos de la producción de vino en un depósito del yacimiento tardoantiguo del Pla de ses Figueres (Cabrera, islas Baleares), correspondiente a su ocupación en los siglos V-VI; en un depósito hallado en una de las habitaciones anexas al baptisterio de la basílica de Son Peretó (Mallorca, islas Baleares) (Pecci et al., 2013a, 2013c) y en otro excavado en la villa romana de Sa Mesquida (Calvià, Mallorca), que había sido previamente interpretado como un depósito para la decantación de arcilla por la presencia de un horno de cerámica cercano. En este caso, la combinación del estudio del depósito y de algunas ánforas de importación (Cau et al., 2018) permite demostrar que probablemente en la villa se consumía vino producido tanto localmente como importado (fig. 3).

También se han estudiado bases de prensas utilizadas para la producción de vino (McGovern et al., 2013).

Asimismo, el estudio del pavimento de la instalación productiva romana de Lecce ha permitido confirmar su uso para la producción de aceite de oliva, aunque se haya detectado la presencia de aceite de ricino en una muestra, posiblemente debida a la caída accidental de aceite usado para la iluminación o al depósito de un aceite diferente del que se producía en la instalación productiva (Pecci y D'Andria, 2014).

Un dato interesante que los análisis de todos los depósitos ponen en evidencia es la presencia de residuos de resina de Pinaceae en las muestras. El uso de productos a base de Pinaceae en época romana y tardoantigua era una práctica común para recubrir dolia y ánforas. Sin embargo, estos datos permiten sugerir que es posible que se usase también para la impermeabilización de estructuras productivas y, en particular, las de vino.

De entre las investigaciones que estamos llevando a cabo en diferentes yacimientos, destacan dos casos, tanto por su novedad como por ser los ejemplos conocidos, a día de hoy, más antiguo y más reciente cronológicamente, de evidencia directa de producción de vino en Cataluña, gracias al análisis de residuos (Pecci, en prensa a). El primero de ellos es el de Coll del Moro (Jornet et al., en prensa), donde se ha hallado una instalación productiva del siglo III a. C., con reutilización en el siglo II a. C. (Pecci, en prensa a). El otro, es el de una prensa y un depósito conectados por medio de un canal y tallados en la roca, hallados en Olèrdola (Alt Penedès), donde los resultados de los análisis de la muestra de la prensa indican la presencia de ácido tartárico. Aunque la datación del uso de este tipo de estructuras es extremadamente difícil, la ocupación de esta parte del yacimiento se puede fechar alrededor de los siglos X-XI d. C. (Esteve et al., 2018) (fig. 4).

Ambos estudios son interesantes y abren nuevas perspectivas, tanto por el marco cronológico que abarcan como por el tipo de material analizado. El del yacimiento del Coll 

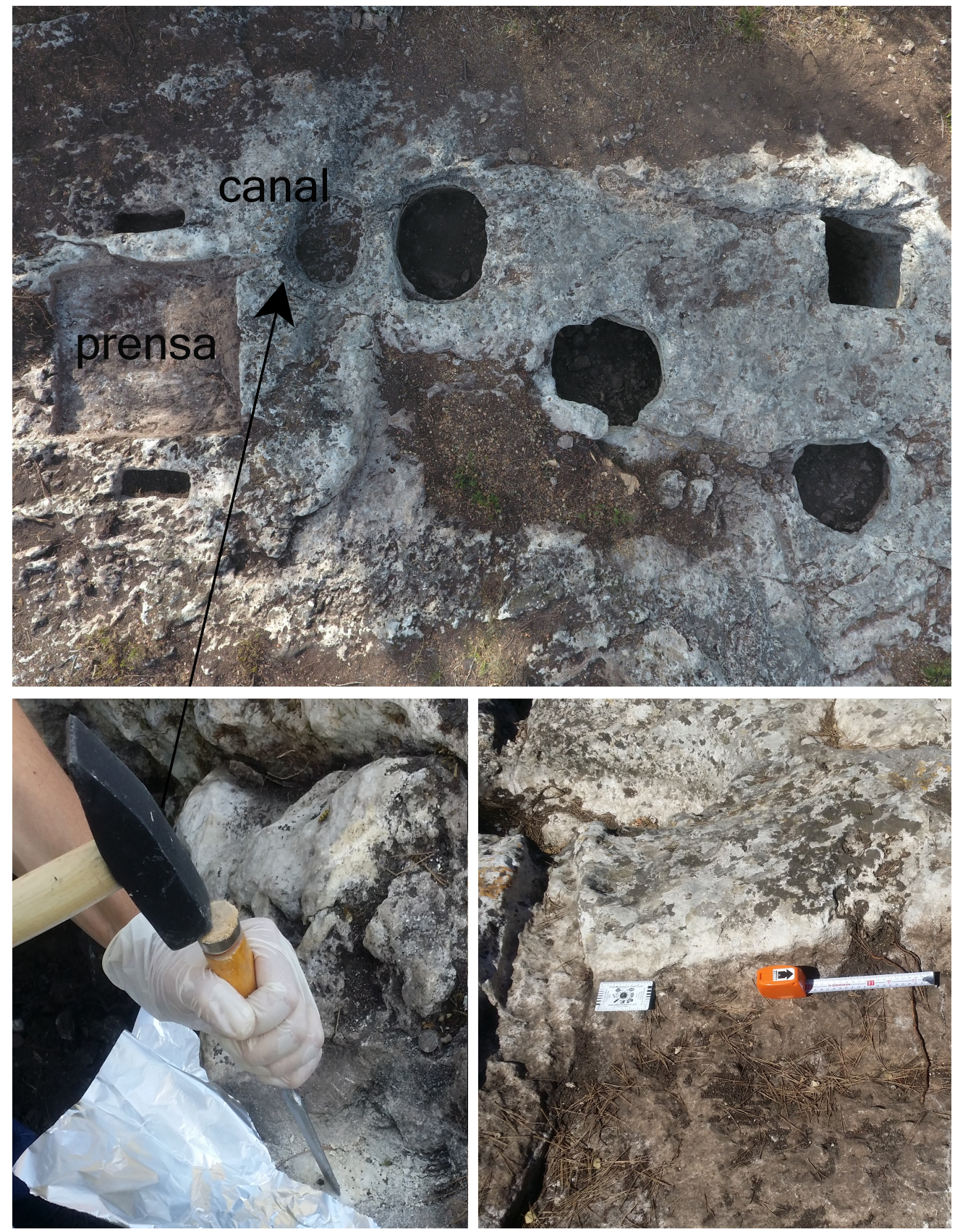

Figura 4. Instalación de producción de vino e imágenes del muestreo en Olèrdola (modificado de Esteve et al., 2018, cortesía de G. Ripoll y N. Molist). 
del Moro demuestra que también la arcilla pisada puede ser analizada, no solo en el caso de pavimentos de yacimientos arqueológicos de diferentes áreas del mundo sino también de estructuras productivas vinarias. El caso de Olèrdola ha demostrado que la piedra, en este caso roca calcárea, puede ser objeto de análisis de residuos. Esta característica podrá ser aprovechada en un futuro para indagar, con las debidas precauciones, otras instalaciones productivas talladas en la roca (Pecci, en prensa $a$ ).

Las instalaciones para la producción de salsas y salazones de pescado son, también, estructuras susceptibles de ser examinadas. Caracterizadas normalmente por la presencia de diferentes depósitos/piletas organizados alrededor de un patio en el que se realizaban las tareas de preparación (como, por ejemplo, cortar y ocasionalmente limpiar el pescado) (Bernal, 2019). El estudio de casos arqueológicos donde se conservan restos visibles del producto procesado demuestra que las superficies de pavimentos, depósitos y cerámicas presentan concentraciones de ácidos grasos y fosfatos, y la GC-MS ayuda en ciertos casos a reconocer los marcadores del pescado (Bernal et al., 2020; Garnier et al., 2019; Pecci et al., 2018). Gracias a la aplicación de análisis de residuos es posible entender la función de las instalaciones y, a veces, identificar los marcadores de productos específicos, como ponen en evidencia algunos depósitos de Baelo Claudia y Troia (Garnier et al., 2019). Cuando se preservan los residuos sólidos de los contenidos de los dolia o piletas es posible experimentar para llegar a obtener sustancias similares a los procesados que, en algunos casos, pueden llegar incluso al mercado (García Vargas et al., 2014). El estudio de los productos experimentales podría acercar a una «arqueología de los sentidos» y del gusto en particular (Alexandre-Bidon, 2005; Hamilakis, 2013; Rudolph, 2018), permitiendo estudiar "científicamente» sabores y olores del pasado, como han mostrado recientemente Rodríguez Alcántara y colegas (2020).

En la investigación de las instalaciones de producción de alimentos se puede abordar también la cuestión de la distribución espacial de las actividades. Durante y después de la producción de alimentos, los líquidos son trasvasados de un recipiente a otro y, en este proceso, son derramados en el suelo y absorbidos por este. Estudios etnoarqueológicos de áreas de producción y almacenamiento de vino, aceite y pulque (una bebida fermentada a base de jugo de agave, consumida por los pueblos mesoamericanos) han identificado residuos orgánicos en los pavimentos de estos espacios (Pecci et al., 2013b, 2013c, 2017b). A nivel arqueológico, por ejemplo, se ha conservado la «suciedad» de la producción del garum en la llamada Bottega del Garum de Pompeya (Bernal et al., 2020; Pecci et al., 2018). También es posible reconocer los espacios destinados a conservar las uvas o aceitunas antes de iniciar el proceso productivo. El simple hecho de dejarlas apiladas en algún punto implica que se prensen ligeramente y derramen el líquido contenido en su interior, como demuestra la investigación etnoarqueológica en molinos de aceite en Binibassí (Mallorca) y en Toscana (Pecci et al., 2013b).

Las instalaciones productivas permiten también el estudio de los recipientes de cerámica para entender qué sustancia fue producida y si se usaron sustancias particulares en su conservación (por ejemplo, la pez o la cera de abeja). En la ya citada Bottega del Garum 
de Pompeya fue posible analizar seis dolia en cuyo interior se recuperaron los restos del pescado utilizado para la producción de garum. Los análisis han identificado, además de la presencia de vino, una reutilización de los dolia derivada de la producción de un producto a base de pescado como el oenogarum y de abundante pez usada para impermeabilizarlos (Pecci et al., 2018).

En la llamada Villa de Augusto, en Somma Vesuviana (Italia), se combinó el estudio de los dolia y los depósitos para confirmar la naturaleza vinaria de la instalación productiva (Allevato et al., 2012). También hay vino en dos dolia de Butrinto, en Albania (Pecci y Cau, 2020), y en dos fragmentos de dolia posiblemente asociados a una estructura productiva, hallados en el yacimiento de Plaça Major - Horts de Can Torras (Castellar del Vallès) (Inserra et al., 2015).

Por otro lado, es importante recordar que el estudio de pithoi del Neolítico en Turquía y Grecia ha permitido abordar el tema de las producciones de vino más antiguas (Barnard et al., 2011; Garnier y Valamoti, 2016; McGovern et al., 2017).

El estudio de los espacios para la producción de queso es otra cuestión que solo se ha abordado marginalmente hasta ahora, pero que tiene la posibilidad de brindar resultados interesantes. El consumo de derivados de la leche es un tema muy en boga y sobre el cual existe una extensa bibliografía publicada. Los trabajos realizados por Copley junto a otros autores $(2003,2005)$ abrieron una importante línea de investigación para diferentes periodos que ha permitido buscar las raíces de la introducción de los derivados de la leche en la dieta humana combinando diferentes técnicas de análisis (Dunne et al., 2012, 2019; Evershed et al., 2008; Salque et al., 2013). Sin embargo, sería también importante abordar el estudio del espacio en estructuras donde se producían los quesos para determinar sus trazas en los pavimentos. Un ejemplo de los residuos que pueden ser detectados es el de una cabaña de pastores sardos que había sido abandonada algunos años antes, en la que se ha identificado por medio de spot tests la presencia de ácidos grasos (fig. 5).

Asimismo, las áreas destinadas al sacrificio de animales son susceptibles de análisis. Debido a que la sangre es rica en proteínas, lípidos y fosfatos, la superficie del pavimento de estas áreas se caracterizará por la presencia de concentraciones de estos compuestos químicos (Pecci, 2004; Pecci et al., 2017a).

\subsection{La conservación, almacenamiento y transporte de alimentos}

El análisis de residuos puede ser aplicado al estudio de los envases de cerámica —principalmente ánforas y dolia - y los espacios destinados a la conservación, almacenamiento y/o transporte, que es la siguiente fase del ciclo de vida de los alimentos.

El estudio de los dolia de contextos de almacenamiento y transporte ha sido poco explorado, pero merece ser ampliado en el futuro, en paralelo al estudio de los entornos de producción. Un ejemplo de su potencial es el análisis de algunos dolia localizados en el almacén del campamento militar de Thamusida, en Marruecos (siglo I d. C.), donde se 

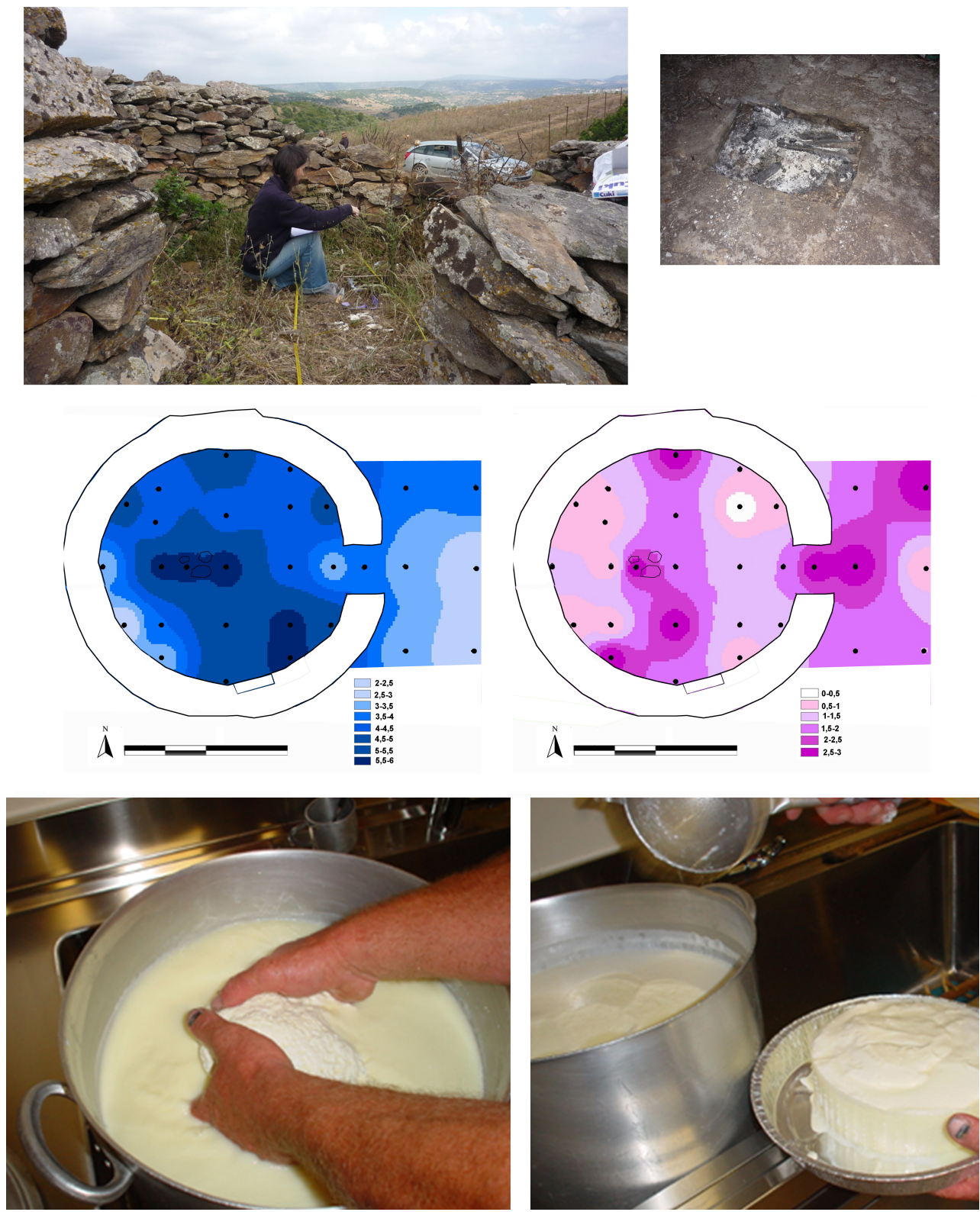

Figura 5. De arriba a abajo: muestreo de una cabaña de pastores abandonada en Cerdeña y foto de los restos de fogón usado para hacer el queso; mapa de distribución de fosfatos (azul) y de ácidos grasos (rosa) del pavimento de la cabaña obtenidos aplicando spot tests desarrollados por Barba (2007). En el centro se encontraba el hogar para calentar la estancia y fabricar el queso. La escala de fosfatos es 0-6, la de ácidos grasos 0-3. Abajo: fotografías de la producción de queso siguiendo las normas de higiene actuales usando materiales que no pueden ser objeto de análisis de residuos. 
identificaron residuos de vino, productos animales y aceites vegetales destinados al abastecimiento del propio campamento (Pecci et al., 2016b).

La posibilidad de estudiar dolia o pithoi prerromanos resulta de gran interés. En la llamada Casa delle Anfore del yacimiento etrusco de Marsiliana, en Toscana, se excavó una estructura completa, con un gran número de dolia, que fue construida en el siglo vi y se usó hasta los siglos v-IV a. C. Los resultados indican la presencia de vino en cinco de los once dolia analizados (fig. 6). Entre los restantes, en dos no hay residuos, lo que induce a pensar en un uso para almacenar agua o productos que no pueden ser identificados con los análisis realizados (un dolium, en particular, se encuentra conectado a un canal de desagüe del patio); otros contenían aceites vegetales y productos animales. Al igual que los dolia de las villae romanas y tardoantiguas, los de la Casa delle Anfore estaban recubiertos con abundante pez de Pinaceae, lo que indica que es una práctica tecnológica en uso en épocas anteriores a la romana (Pecci, en prensa b; Zifferero et al., 2011).

En esta fase del ciclo de vida de los alimentos interesa señalar el uso de ánforas para el transporte de productos comestibles líquidos o sólidos como vino, aceites, salsas de pescado, pescado salado y frutos secos. Las ánforas siempre han sido cruciales para la interpretación de la economía y el comercio antiguos en el Mediterráneo y su estudio proporciona datos fundamentales para la investigación del movimiento de las mercancías puesto que son recipientes de uso frecuente, que se encuentran en grandes cantidades en los yacimientos arqueológicos y son materiales de diagnóstico con tipologías bien establecidas y orígenes generalmente identificables (Bernal et al., en prensa; Bonifay, 2004; Bonifay et al., 2015; Carreras Monfort, 2000; Empereur y Picon, 1989; Panella y Rizzo, 2014; Remolà i Vallverdú, 2000; Reynolds, 2010a, 2010b). Sin embargo, la importancia de las ánforas radica no tanto en el hecho de ser recipientes en sí mismas, sino como evidencia indirecta de los productos que eran transportados en ellas y consumidos en los lugares de destino.

Aún a pesar de los numerosos estudios anfóricos de carácter tipológico y de área de proveniencia, la forma más directa de conocer su contenido es identificar el propio contenido si se ha conservado, dado que, al tratarse de un material orgánico, muy a menudo ha desaparecido. En estos casos, se pueden aplicar análisis de los residuos químicos preservados en los poros de la cerámica. Los trabajos realizados por varios investigadores a partir de la década de 1970 han sido fundamentales en este sentido. Se han llevado a cabo análisis de ánforas de origen y periodos diferentes (entre ellos, Bernal-Casasola, 2015; Garnier, 2007; Garnier y Pecci, en prensa; Garnier et al., 2009, 201 1; Pecci, 2009a, 2018; Pecci y Cau, 2010, 2014a; Pecci et al., 2010, 2017c, en prensa; Rageot et al., 2019; Romanus et al., 2009; Woodworth et al., 2015). Los resultados de los análisis de residuos en ánforas confirman las hipótesis arqueológicas sobre los contenidos de algunas de ellas. Un ejemplo es el caso de determinadas ánforas béticas Dressel 20 halladas en el Testaccio, que son ánforas olearias, o de las Dressel 2-4 halladas en Oplontis B (Pompeya), que eran vinarias (Pecci y Cau 2014a; Pecci et al., 2017c). En otras ocasiones, los resultados analíticos sirven para proporcionar informaciones sobre el contenido de tipologías anfóricas, desconocido hasta el momento. El análisis de ánforas revela que podían transportar aceites diferentes al de 
oliva, como el de ricino, moringa, de Brassicaceae, algunos posiblemente usados para la alimentación y otros para usos medicinales, como bases de ungüentos, o para la iluminación (Garnier et al., 2009; Pecci, 2009a, 2018; Pecci et al., 2010). De hecho, el análisis de residuos ha contribuido a mostrar la importancia de estos aceites y a plantear la necesidad de un estudio más sistemático.

Los trabajos recientes ponen en evidencia la importancia de no minimizar el fenómeno de reutilización de las ánforas; este es el caso, por ejemplo, de los hallazgos de vino y aceite en el mismo envase, que, a diferencia del pescado y del vino, o del pescado y del aceite, no habrían podido hallarse al mismo tiempo en la misma ánfora. Debido a que no podemos establecer el orden de absorción de las sustancias, puede ser difícil entender cuál fue el contenido originario y cuál el inducido por la reutilización (Garnier y Pecci, en prensa; Pecci y Giorgi, 2019; Pecci et al., en prensa). En este sentido, será solo la combinación del estudio de la procedencia de las ánforas y de un gran número de análisis de residuos lo que permitirá identificar los patrones de uso de los diferentes tipos anfóricos. Finalmente, el tipo de contexto donde se han encontrado las ánforas es de vital importancia (p. ej., si se trata de un pecio, un puerto, o un yacimiento del interior), ya que puede influir en la posibilidad de que las ánforas hayan sido reutilizadas (Pecci, 2019).

Los argumentos expuestos sobre las ánforas confirman la prudencia con la que han de ser utilizadas como indicadores de comercio y consumo de productos en los yacimientos arqueológicos y ponen de relieve la necesidad de realizar análisis. Solo así, sobre sólidas bases científicas, se pueden determinar cuáles eran los contenidos — no necesariamente únicos- de los diferentes tipos de ánforas.

Por el momento, estamos trabajando en esta dirección, empezando por la investigación de algunas tipologías de ánforas de los siglos I a. C. - I d. C. procedentes de la Bética, el África Proconsular y el Mediterráneo oriental y halladas en Italia y en el sur de la península ibérica, en el marco del proyecto I+D «Ánforas romanas y análisis de contenidos. El consumo de alimentos de la Baetica, África y el Oriente levantino en Gades, Roma y Pompeii (siglos I a. C. - I d. C.)", que dirigimos con P. Reynolds (RACAMed - HAR2017-84242-P).

La primera cuestión que hemos logrado abordar es la de los envases usados para la exportación de vino de la Baetica. Esta región es conocida por la producción y exportación de aceite y pescado; sin embargo, se ha propuesto que produjo también ánforas destinadas al transporte de vino, productos a base de vino o mezclados con este, como las Haltern 70 (García Vargas, 2012), sus antecesoras, las ánforas ovoides del siglo I a. C., y las imitaciones béticas de las ánforas típicas de época republicana en la península itálica, las Dr. 1 (Étienne y Mayet, 2000). En el seno del proyecto se han analizado casi cincuenta ánforas béticas, en general ánforas de cuerpo ovoide de tipo 1 y 5 halladas en Cádiz, en el contexto de El Olivillo (Bernal-Casasola y Vargas, 2019). El resultado de los análisis demuestra el transporte de vino o derivados en la mayoría de las ánforas estudiadas hasta el momento, pero no se trata de un envase con un uso del todo estandardizado, ya que en algunos casos se hallan contenidos diferentes y posibles mezclas de productos y/o reutilizaciones (BernalCasasola et al., 2019a, 2019b; Pecci et al., en prensa). 

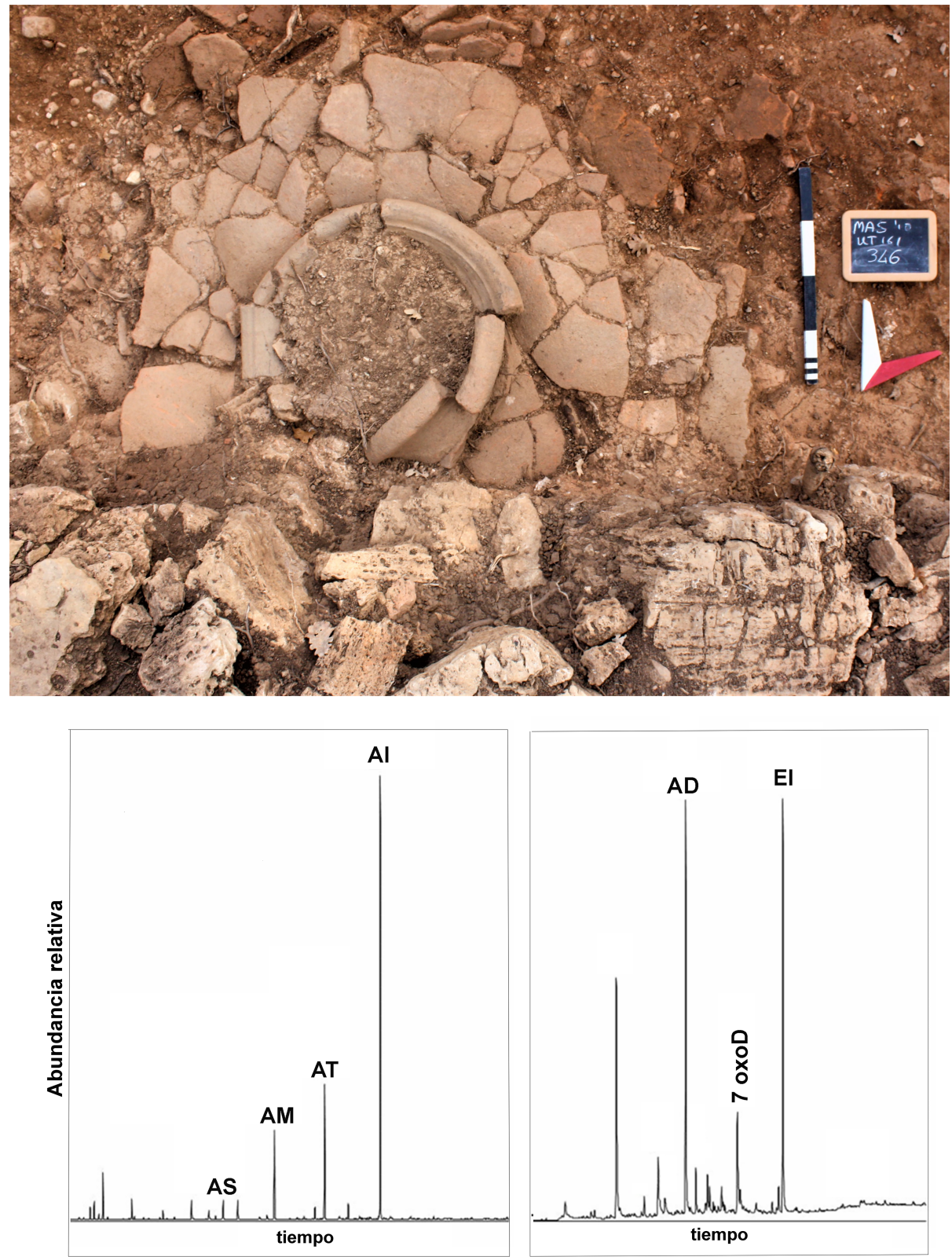

Figura 6. Dolium etrusco encontrado in situ en el yacimiento de Marsiliana y cromatogramas parciales donde se pueden observar los marcadores del vino: ácido succínico (AS), ácido málico (AM), ácido tartárico (AT) y ácido isocítrico (Al) y los marcadores de la pez de Pinaceae i ácido dehidroabiético (AD), ácido 7-0xo dehidroabiético (7-0xoD) y el metildehidroabietato (MD). El es el estándar interno (modificado de Pecci, en prensa). 
En el marco del mismo proyecto estamos investigando otros tipos de ánforas para establecer una base de datos de los contenidos identificados a través del análisis químico, entre ellos, ánforas africanas tempranas producidas en la zona noroccidental de Túnez (Africa Proconsularis) (Ben Jerbania, 2013; Bonifay et al., 2015; Contino y Capelli, 2013) y ánforas orientales.

Es interesante señalar que se ha iniciado también el estudio de ánforas prerromanas y medievales. Por ejemplo, se han analizado ánforas en yacimientos celtas (siglos VII-V a. C.) halladas en Europa Central (Rageot et al., 2019) y un ánfora etrusca hallada en Lattara (McGovern et al., 2013), y en cuanto a las tardías, ánforas globulares de los siglos VIII-IX d. C. de Comacchio (noreste de Italia), y ánforas Gunsenin 3 y 4 procedentes del Mediterráneo oriental (Pecci, 2018; Pecci et al., 2020b). Por último, es necesario recordar que los alimentos podían ser transportados también en otras formas cerámicas que son susceptibles de ser analizadas, como por ejemplo las jarras de fondo plano o las llamadas olle acquarie medievales italianas.

El estudio sistemático de un número cada vez mayor mayor de ánforas y otros envases para el transporte permitirá una mejor comprensión del movimiento de los productos, y de los alimentos en particular, en el pasado. Sin embargo, este tiene que integrarse con el de la proveniencia de las ánforas y los datos epigráficos, como han hecho, por ejemplo, Cau y otros autores (2018), en el caso de ánforas Dressel l encontradas en Sa Mesquida (Mallorca). En el futuro habrá también que integrar cada vez más el análisis de restos microbotánicos en las ánforas, como el polen (Arobba et al. 2014; Rösch, 2005), y de restos arqueozoológicos (Bernal et al., 2020).

El vino, el vinagre, la grasa animal, el aceite u otros productos podían ser, además del contenido principal de la cerámica, también un líquido empleado en la conservación de otros productos. Debido a que por el momento no es posible diferenciar entre el vino y sus derivados, cuando se identifican sus biomarcadores es necesario contemplar la posibilidad de que se trate de vinagre de uva y constituya el medio líquido o semilíquido en el que se preservaban otros productos.

\subsubsection{El recubrimiento de los envases}

La investigación de las cerámicas implica también el estudio de la aplicación de un tratamiento de los envases. De hecho, la mayoría de los envases conocidos para el almacenamiento de productos líquidos (principalmente ánforas y dolia) presenta recubrimientos, en general de naturaleza orgánica, en forma de resina o pez de Pinaceae (Colombini et al., 2005; Garnier y Pecci, en prensa; McGovern et al., 2017).

Este recubrimiento tuvo — además de la impermeabilización de los envases- una función de conservación de los alimentos contenidos y sirvió, quizá, para darles sabor.

Por último, es posible que el recubrimiento sirviese para proteger los envases mismos de los ataques químicos y físicos ocasionados durante el proceso de fermentación de los 
productos contenidos, como con el vino y posiblemente el garum, o de la sal, en el caso de la producción de derivados del pescado.

Recientemente se ha identificado también la presencia de azufre en algunas de las muestras de cerámicas analizadas. Se trata de dolia, hallados en Aspromonte, Calabria, y ánforas de diversos tipos (Garnier et al., 2011; Pecci, 2016, 2018), así como de cerámicas de diferentes formas de épocas más antiguas, en particular de la Edad del Bronce (Pecci et al., 2020a).

Garnier y sus colegas han propuesto el uso del azufre para la impermeabilización de los envases (Garnier et al., 2011). Efectivamente, los experimentos que efectuamos quemando azufre en recipientes cerámicos producen una capa negra de aspecto similar al de la brea. Aun así, se podría sugerir también el uso de este producto para desinfectar los envases y conservar mejor su contenido. De facto, el azufre tiene propiedades antimicrobianas y antioxidantes y se usa para reducir el ennegrecimiento y retrasar la fermentación del vino (Henderson, 2009; Jacobson, 2006; Rose, 1993). El empleo del azufre para limpiar y desinfectar los barriles de madera usados para contener el vino ha sido una práctica habitual hasta hace pocos años. De hecho, cerca de la nueva cosecha, los barriles empleados para almacenar vino durante casi un año, se vaciaban (en ocasiones usando la fuerza de trabajo de niños de hasta diez años, que podían llegar a entrar en los recipientes), se limpiaban mecánicamente y se quemaba azufre en ellos. Los trabajos experimentales preliminares que realizamos siguiendo el protocolo obtenido gracias a la entrevista de personas mayores en Italia, demuestran que esta actividad deja residuos compatibles con los que se encuentran al realizar análisis de residuos de materiales arqueológicos (Pecci, 2018; Pecci et al., $2020 a$ ). Es interesante observar que el azufre se identifica, en la mayoría de los casos, en los envases en los que el ácido tartárico también está presente, insinuando una posible relación preferencial con la conservación de vino, aunque existan excepciones.

El uso de productos para el recubrimiento de los envases podría sugerir contactos a larga distancia. En época romana existió un movimiento importante de pez/brea para esta finalidad, como muestra el hallazgo de ánforas y otros contenedores llenos de pez, principalmente en los pecios. Es posible que este producto sirviera para el mantenimiento de los barcos, pero también debió de transportarse para el uso en la impermeabilización de ánforas, dolia y otros tipos de envases. En Oplontis B y en la figlina de Albinia (Toscana) se han localizado bloques de pez que debieron tener esta función. La pez, más común que el azufre, no podía producirse en cualquier lugar y su producción debió realizarse en emplazamientos relativamente altos. La pez de Pinaceae más conocida en la Antigüedad era la pez Bruttia, de la actual Calabria, usada para impermeabilizar las ánforas y para sellar los opercula de los dolia empleados en la producción de vino, que era, a menudo, exportado en ánforas Dressel 1 (Accardo, 2000; Sangineto, 1992) (fig. 7).

Si se confirma el uso de azufre en la impermeabilización de los envases o la conservación de los alimentos, también el hallazgo de esta sustancia podría sugerir contactos a larga distancia. De hecho, los depósitos de azufre comercializable de alta pureza fueron explotados y transformados, principalmente en Sicilia, desde principios de la Edad del 

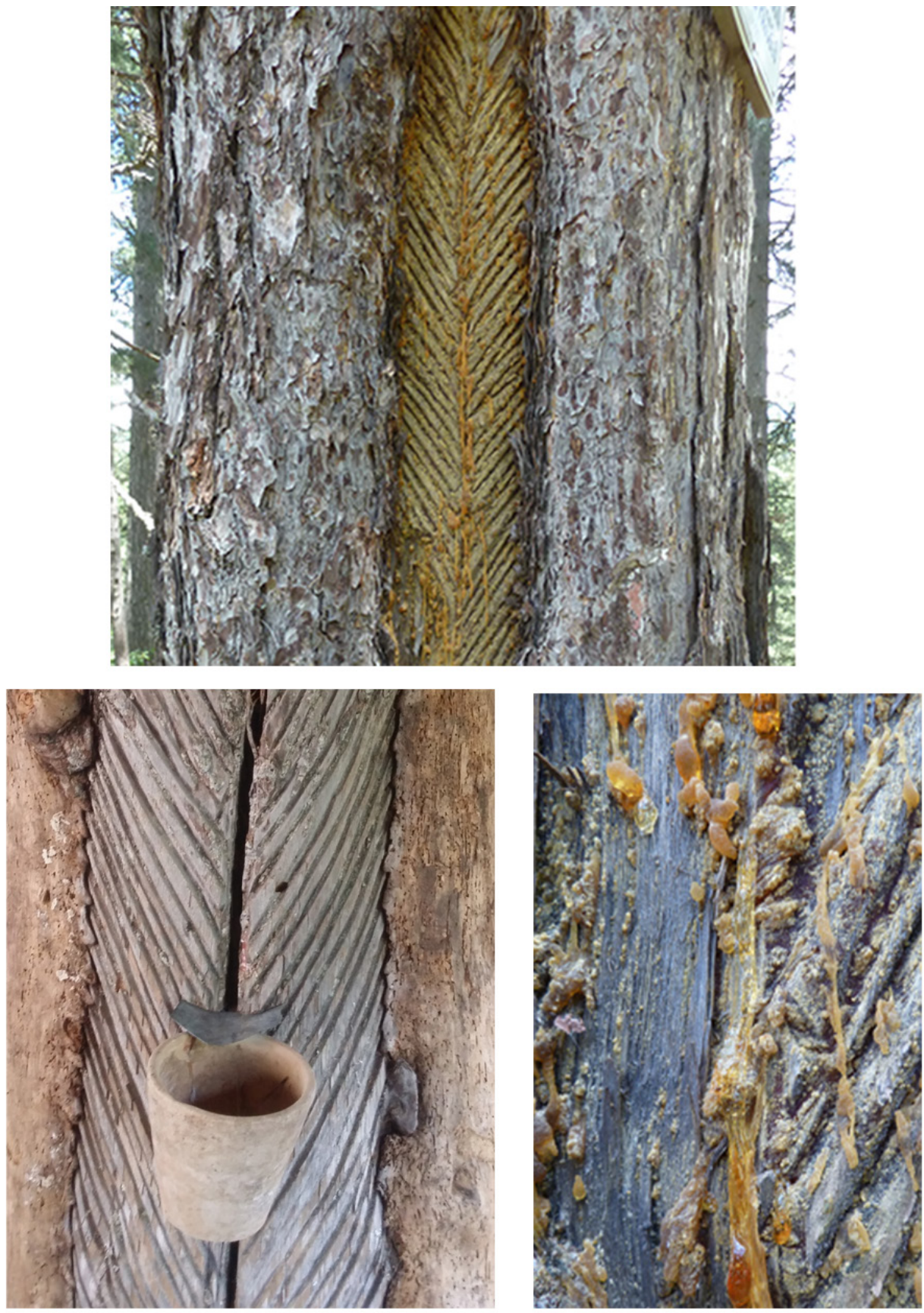

Figura 7. Extracción de la resina de Pinus nigra laricio en Calabria. 
Bronce Medio (MBA) (Russell, 2011). De cualquier forma, son necesarios más estudios que faciliten la comprensión del origen del azufre identificado en los envases arqueológicos.

\subsubsection{Los almacenes}

Las áreas de almacenamiento, al igual que en el caso de las instalaciones productivas, pueden ser objeto de análisis químico. A día de hoy, los análisis en este tipo de espacios son escasos, pero su potencial ha de ser evaluado cuando no se han preservado materiales que puedan indicar su función. Realizar análisis químicos de los pavimentos de estas estructuras facilita la comprensión de qué productos eran almacenados y la organización espacial del almacén. La conservación de los residuos y la posibilidad de efectuar análisis dependerán, entre otras cosas, del tipo de material usado para la construcción de los pavimentos: si se trata de madera es complejo dada la dificultad en diferenciar los compuestos de la madera y los de las sustancias derramadas, mientras que en almacenes con pavimentos de opus signinum o baldosas es más fiable.

El almacenamiento de alimentos es un elemento importante de la reflexión. Este se realizaba principalmente en las instalaciones productivas y en los lugares de consumo. Además, eran primordiales los almacenes relacionados con la distribución de los alimentos, como los de los puertos. Solo por citar dos ejemplos, se pueden mencionar para época romana los de Portus y en la época tardoantigua los de Classe (Augenti, 2019).

Si los productos almacenados eran sólidos, como en el caso de granos, es oportuno llevar a cabo análisis macro y microbotánicos. La investigación llevada a cabo en un almacén medieval en Miranduolo (Toscana) ha demostrado el potencial de un estudio integrado que combina el análisis botánico y de residuos (en este caso con spot tests), poniendo en evidencia la distribución espacial de los diferentes granos almacenados y, a nivel químico, la presencia de fosfatos y la ausencia de ácidos grasos, confirmando que el espacio no era utilizado para realizar otro tipo de actividades susceptibles de enriquecer químicamente el pavimento (Di Pasquale et al., 2006).

Sin embargo, si los productos eran líquidos conservados en recipientes de cerámica, cuando un envase se rompía o cuando su contenido se trasvasaba a otro envase, es posible que parte del líquido se derramase en el suelo provocando así el enriquecimiento de las superficies del pavimento. Los patrones de distribución de los residuos químicos de los pavimentos de estas áreas dependen del tipo de materiales almacenados.

\subsection{La preparación de alimentos}

Los alimentos, para que puedan ser consumidos, en muchas ocasiones, tienen que ser preparados. Alonso y otros (2019), en la ponencia presentada durante la V Reunión Oikos de Bioarqueología organizada por la Associació Catalana de Bioarqueologia (ACBA), propusieron diferenciar entre un procesamiento con cocción y un procesa- 
miento sin cocción. Esta segunda actividad incluye acciones como mezclar, moler y/o sazonar los alimentos.

$\mathrm{Al}$ igual que en las fases anteriores del ciclo de vida de los alimentos, las actividades realizadas en esta fase implican que los diferentes materiales involucrados en el proceso de preparación de alimentos, como las cerámicas de cocina, los morteros, las cucharas u otros utensilios usados para cortar, mezclar y cocinar, se enriquezcan químicamente.

De todas las fases del ciclo de vida de los alimentos, la de la cocción es la que más ha llamado la atención de los investigadores de las diferentes disciplinas. Como LéviStrauss que consideró que el acto de cocinar ha jugado un papel clave en la cultura y en la sociedad, hasta tal punto que lo situó en el centro del discurso para comprender el salto de la humanidad desde la naturaleza a la cultura (Lévi-Strauss, 2008). Esta fase de la cocción deja residuos químicos en las cerámicas, como demuestra el largo recorrido de la investigación y un sinnúmero de publicaciones ya mencionadas a propósito del análisis de residuos en cerámicas.

El estudio de residuos se ha centrado principalmente en identificar los productos animales, permitiendo establecer el uso preferente de las cerámicas (p. ej. para productos lácteos, marinos, de rumiantes, etc.). Sin embargo, el componente vegetal fue mayoritario, en especial en algunas épocas. Durante mucho tiempo solo se ha podido sugerir la mezcla de productos animales con productos vegetales en la cocción en ollas combinando el estudio de las cerámicas con el arqueozoológico y arqueobotánico (Buonincontri et al., 2017) (fig. 8). El hecho de que algunas cerámicas de cocina presenten residuos muy escasos se debe, con toda probabilidad, a que algunas sustancias contenidas en ellas no dejan residuos, como el agua, o que los análisis realizados no podían detectar, hasta hace poco, cereales y legumbres que con mucha probabilidad eran preparados en ellas. Hoy en día, con el análisis de residuos, es posible identificar algunos cereales como el maíz o el mijo y se están investigando otros (Hammann y Cramp, 2018; Heron et al., 2016; Reber et al., 2004). Asimismo, es importante integrar el estudio del análisis de residuos con el de almidones (Barton y Torrence, 2015).

Finalmente, es conveniente destacar el consumo de aceite en la cocina sobre todo en el Mediterráneo y en determinadas épocas. La cocción del aceite produce patrones de degradación típicos, reconocidos en algunas ocasiones en cerámicas de cocina tardoantiguas de las islas Baleares (Pecci y Cau, 2014b) y Cataluña (Inserra et al., 2015) y medievales de Toscana (Buonincontri et al., 2017).

La investigación de los residuos ha permitido confirmar que es posible considerar «cerámicas de cocina» también algunas jarras de pasta de ganulometría gruesa que presentan trazas de hollín en la parte opuesta al asa. Este es el caso de algunas jarras medievales toscanas y algunas tardoantiguas catalanas, que, además de las trazas de hollín, presentan residuos de productos animales y, en ocasiones, de Brassicaceae (Inserra et al., 2015; Pecci, 2009a; Pecci y Cau, 2014b).

A nivel práctico, a menudo, no es posible observar diferencias importantes entre los residuos conservados en las diversas formas cerámicas, como cazuelas más o menos pro- 

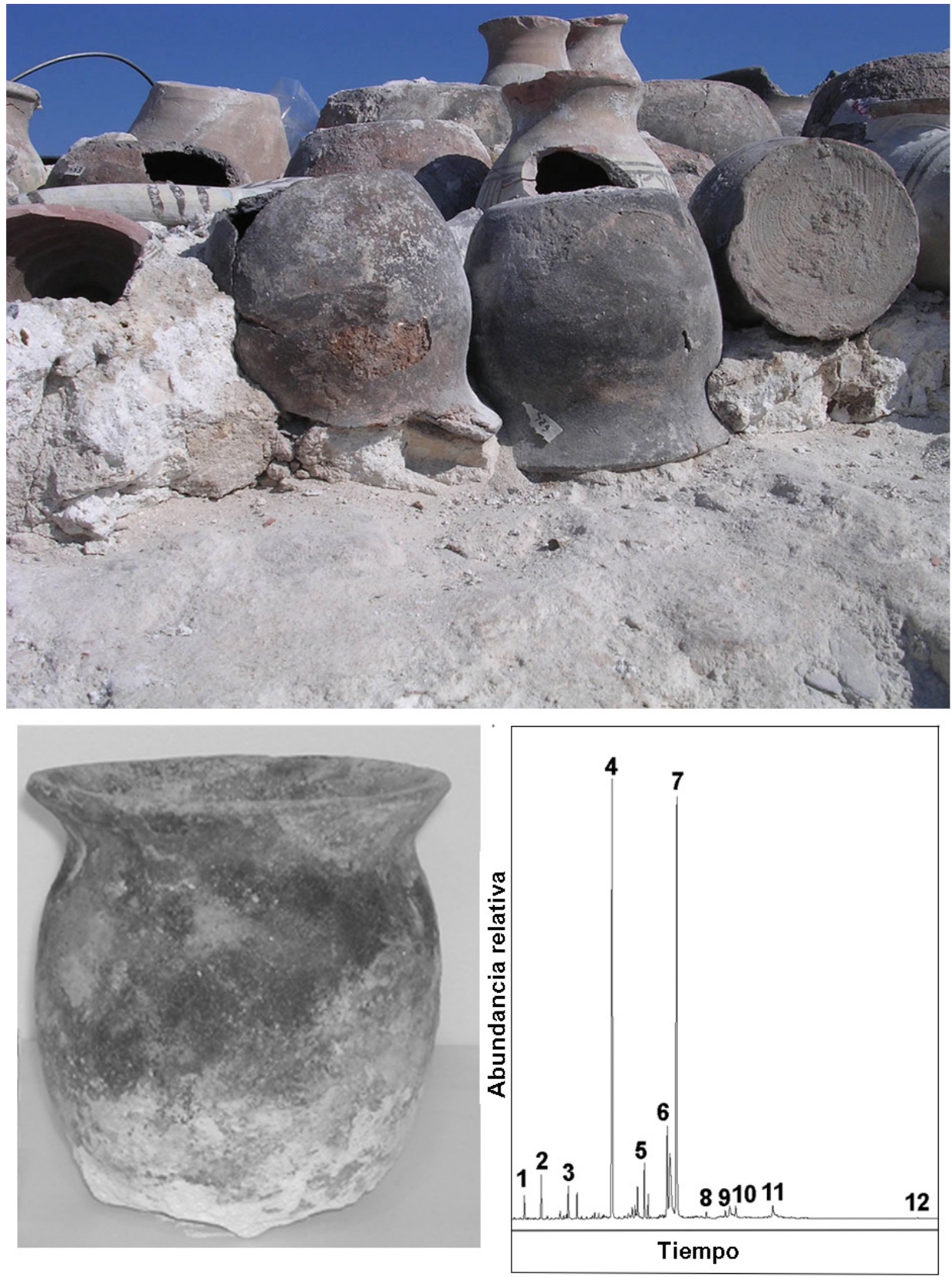

Figura 8. Fotografía de las cerámicas halladas en el relleno de la bóveda de la iglesia de Sant'Antimo en Piombino (cortesía de G. Bianchi) y cromatograma parcial del extracto lipídico de la muestra de una olla. La abundancia de ácido palmítico (4) y ácido esteárico (7), así como la presencia de colesterol (11) sugieren la cocción de productos de origen animal (el 10 es el estandar interno, 5ul). 
fundas, o entre ollas y cazuelas, o incluso cerámicas tecnológicamente distintas (vidriadas vs. no vidriadas) probablemente porque eran las formas de preparar los alimentos - hervirlos, asarlos y prepararlos según las distintas recetas- las que cambiaban y no tanto el tipo de alimentos preparados (Inserra et al., 2015, 2016c; Pecci y Cau, 2014b). Sin embargo, en algunos casos existen patrones de uso muy claros (Roffet-Salqué et al. 2017) y hay ocasiones en las que es posible reconocer el consumo de alimentos diferentes asociados a identidades particulares, como en el caso de algunas cerámicas usadas por la comunidad judía en la Oxford medieval, en las que destaca la ausencia de residuos de cerdo ${ }^{1}$.

Gracias al estudio de las formas cerámicas y de los residuos químicos es factible evidenciar los modos de cocción. Como ya se ha avanzado, la presencia diferencial de residuos en la pared, borde y fondo de las cerámicas está relacionada con el modo de cocción (Charters et al., 1993, 1997). Por ejemplo, la Edad Media toscana se caracteriza por lo que se ha llamado el "monopolio de lo hervido» (Montanari, 1989). Esto consistía en hervir las carnes poco tiernas de los animales sacrificados en edad adulta y criados en su mayoría de forma semiselvática, para hacerlas comestibles. El estudio de la distribución de los residuos en diferentes formas cerámicas medievales toscanas indica que no solo las ollas, sino también las cazuelas, se usaban para cocinar con abundante agua y, por lo tanto, para «hervir» (Pecci, 2009a).

Asimismo, es posible integrar el análisis de residuos con los datos arqueozoológicos para identificar además de las especies de animales procesados, también los cortes de los huesos animales que por sus dimensiones podían haberse colocado en las ollas o sartenes usados para la cocción, brindando así información adicional acerca de alimentación y de las formas de preparar alimentos (Buonincontri et al., 2007).

El vino (o sus derivados) es un ingrediente importante en la cocina y se ha podido reconocer gracias a la aplicación de análisis de residuos orgánicos. Se ha constatado en cerámicas de cocina de la Edad del Bronce en el noreste de Italia (Pecci et al., 2020a), en cerámicas tardoantiguas encontradas en Mallorca y en Cataluña (Inserra et al., 2015; Pecci y Cau, 2014b), en cerámicas medievales de la Toscana (Pecci, 2006, 2009) y en una olla de la Casa de Championnet en Pompeya (Toniolo y Pecci, 2020).

En este sentido, pensamos que la interpretación que hacen Drieu y otros autores (2019) de la presencia de ácido tartárico en cerámicas de cocina como producto de contaminación no es la correcta, a menos que se demuestre que la cerámica está contaminada por procesos posdeposicionales o por situaciones específicas del contexto. De hecho, si las muestras de control del terreno indican que no existe contaminación externa, y el análisis se ha realizado correctamente, se puede afirmar que el ácido tartárico deriva del uso de las cerámicas. No solo la cerámica podía servir para almacenar y transportar vino, como en el caso de las ánforas, sino también para preparar recetas en las que el vino, u otros derivados de la uva, como el vinagre o el defrutum, jugaban un papel muy importante. Lo anterior es muy claro si se revisan los recetarios romanos y medievales, en los que muchísimas recetas

1. Edward Biddulph, comunicación personal. 
incorporan estos ingredientes, desde la preparación de salsas como el 'agresto' (arrope) medieval hasta diferentes formas de preparar el garum.

A propósito de la preparación de alimentos, se pueden estudiar también las cerámicas que se usan para moler y mezclar los alimentos, como los mortaria. Si bien el análisis de residuos químicos no permite, por ahora, demostrar el uso de los mortaria para moler cereales (con pocas exepciones, como ya se ha señalado), se ha identificado el procesamiento de alimentos diferentes, posiblemente mezclados en los mortaria, como grasas animales y vegetales y, en ocasiones, en algunos morteros tardoantiguos de Cataluña, además, residuos de vino o sus derivados, lo que refuerza la idea del uso de estos materiales para moler y mezclar sustancias de diversos orígenes (Cramp et al., 2011 ; Inserra et al., 2015).

Un dato interesante que emerge del estudio de residuos en las cerámicas de cocina, es la presencia de un revestimiento a base de resina o brea de coníferas vinculado, con toda probabilidad, a la necesidad de impermeabilizar las cerámicas y hacer que la cocción sea más eficiente, según lo observado por Sempere en la península ibérica y por Schiffer entre los Kalinga (Pecci, 2006, 2019; Sempere, 1982; Schiffer et al., 1994; Skybo, 2013). Esta práctica pudo tener una influencia también en el gusto de los alimentos.

Por último, el estudio de esta fase del ciclo de vida de los alimentos pasa también por el análisis de otros materiales arqueológicos, como son las superficies de las estructuras usadas para la preparación y la cocción (fogones, hornos) y los pavimentos de las cocinas. En particular, las áreas de cocción de alimentos se reconocen por la presencia de ceniza, producida por los fogones, braseros u hornos, que provoca un aumento en el valor promedio del pH del suelo, el cual a menudo alcanza valores superiores a nueve (Barba et al., 1991). Debido a que durante el proceso de cocción pueden derramarse líquidos sobre la superficie de cocción o sobre el pavimento, la detección de residuos químicos en estas superficies es posible. La grasa se escurre cuando se cocina carne a la parrilla, o el líquido se derrama de la olla al hervir en exceso. La etnoarqueología y la arqueología experimental confirman estos patrones (Barba y Bello, 1978; Barba et al., 2014; Pecci et al., 2017a). En el ámbito espacial, la cocción de alimentos se refleja en el enriquecimiento químico de estas superficies (García Álvarez-Busto et al., 2019; Ortiz y Barba, 1993; Pecci, 2013). Si se usan spot tests, el patrón de distribución de los residuos en las zonas de cocción se caracteriza por la presencia de residuos de grasas y residuos proteicos relacionados con los alimentos preparados, que, aplicando técnicas más específicas, como la cromatografía de gases, ayudan a identificar con más precisión algunos de los productos preparados. A diferencia de las anteriores, las áreas de preparación de alimentos — por ejemplo, donde se corta la carne, se limpia y desescama el pescado o se puede batir un huevo- se caracterizan por la ausencia de residuos de ceniza, pero mantienen los residuos de los alimentos procesados. Si se estudian pavimentos en tierra es ideal combinar el análisis de residuos químicos con la micromorfología.

Los ejemplos de estudio químico de áreas de preparación de alimentos realizados en México a partir de la década de 1970 son muy numerosos. Entre ellos destacan los de los complejos arquitectónicos en Teotihuacan (México), ejecutados en el marco de las 
investigaciones de Linda Manzanilla (Ortiz y Barba, 1993; Ortiz et al., 2018). En el área mediterránea cabe mencionar las cocinas de la Bottega del Garum de Pompeya, donde se detectaron los residuos de las grasas sobre la superficie del horno y del pavimento y la cocina de una domus romana en Populonia (Pecci, 2013; Pecci et al., 2018) (véase, fig. 1). Para épocas posteriores se han estudiado las cocinas del monasterio de San Vincenzo al Volturno (Molise), las de una taberna medieval en San Genesio (Toscana) y áreas de preparación de alimentos en cabañas de la Alta Edad Media en Donoratico y Grosseto, ambos en Toscana (Inserra y Pecci, 2011; Pecci, 2009b). En la península ibérica se han estudiado las cocinas de Cornellana (Asturias) (García Álvarez-Busto et al., 2019).

Para conocer con exactitud el tipo de alimentos preparados y cocinados, es necesario realizar análisis con GC-MS y GC-C-IRMS que permitan identificar los biomarcadores de las diferentes sustancias cocinadas; pero no hay que olvidar que las superficies absorben todas las sustancias con las que entran en contacto, es decir, que lo que se detecta es la suma de todos los alimentos preparados/cocinados sobre ellas a lo largo del tiempo.

\subsection{Consumo de alimentos}

La investigación de esta fase del ciclo de vida de los alimentos, su consumo, tiene un gran potencial para abordar el estudio de aspectos de las sociedades del pasado como son la comensalidad, las prácticas de consumo, las formas de servir los alimentos en la mesa, la venta de los alimentos e incluso aspectos rituales. Sin embargo, a pesar de este abanico de posibilidades, esta fase del ciclo de vida de los alimentos es la que menos atención ha recibido por parte de los investigadores que realizan análisis de residuos en cerámicas, a excepción de los contextos funerarios.

Como en las fases anteriores, el estudio de las cerámicas tiene un papel fundamental, dado que permite reconocer las formas de consumo, de servir los alimentos, de «estar en la mesa» y de venta de los alimentos. La vajilla puede reflejar prácticas alimenticias específicas, como comer individualmente en cuencos pequeños o compartir alimentos en cuencos comunales grandes, como se observa por ejemplo en la iconografía medieval. No obstante, ya se ha comentado, el estudio de residuos en cerámicas destinadas al consumo de alimentos es todavía limitado. Intervienen diversos factores. Sin duda, uno importante es que muchas de las cerámicas de consumo son por regla general de pasta fina y a menudo con engobe y pintadas, lo que significa que han absorbido menos residuos que las cerámicas de cocina, caracterizadas por ser muy porosas y en las que, además, el calor facilita la absorción (Evershed, 2008). De hecho, los resultados de los análisis realizados hasta ahora confirman que no es sencillo obtener datos sobre este tipo de contenedores; sin embargo, también indican que su examen es posible y merece la pena. Ejemplos de estudio de materiales usados para servir alimentos y bebidas son los de algunas jarras tardoantiguas y medievales halladas en diferentes contextos medievales de Toscana y de la Antigüedad tardía en Cataluña. La ausencia de residuos en algunas de ellas hace pensar que servían 
para contener agua, mientras que en otras ha sido posible identificar la presencia de vino (Inserra et al., 2015; Pecci, 2009a, Buonincontri et al., 2017; Valdambrini et al., 2006).

En cuanto al consumo de bebidas, el análisis de una copa etrusca de barniz negro hallada en Volterra) y de una copa en cerámica fina hallada en el yacimiento de San Rocco, en Basilicata, indican que es posible estudiarlas y que ambas copas sirvieron para el consumo de vino (Pecci, informes no publicados). También se han estudiado copas de la Edad del Bronce halladas en Italia. En algunas se encuentran residuos de vino, lo que sugiere un consumo de la bebida anterior a la llegada de las poblaciones griegas y fenicias (Pecci et al., 2020a).

Un caso aparte es el consumo ritual de los alimentos. Por ejemplo, es posible analizar los materiales involucrados en los rituales funerarios y las ofrendas a los difuntos, como las ánforas halladas en la tumba de Tutankamón (Guasch-Jané et al., 2004). Garnier ha analizado, en el marco del proyecto MAGI, muchos recipientes cerámicos encontrados en sepulturas de la Edad del Hierro (entre otros, Frère y Garnier, 2017), así como un caldero metálico localizado en la tumba del príncipe de Laveau (Garnier y Dubuis, 2019). También puede ser considerada en esta fase la ofrenda de alimentos a los dioses, quienes los "consumen" ritualmente. Un ejemplo de ello son las cerámicas de un contexto votivo aparecido en el centro de Granada, en algunas de las cuales ha sido posible hallar residuos de vino (Manzano et al., 2016).

En cuanto al estudio de los espacios donde los alimentos eran consumidos, se puede sugerir que algunos de ellos podían salpicar el suelo durante su consumo o ser voluntariamente derramados, enriqueciendo el suelo químicamente. Este factor posibilita realizar análisis con el fin de establecer un patrón de enriquecimiento químico en los pavimentos. Este patrón debe ser similar, aunque menos intenso, al de los lugares de preparación de alimentos que no prevén la cocción, ya que serán los mismos alimentos preparados en las cocinas, que caen al suelo durante su consumo.

El único ejemplo que conocemos para probar el potencial de este tipo de estudios es el que realizamos en una cabaña medieval en Grosseto (Italia), donde se detectaron residuos probablemente derivados del consumo de alimentos alrededor de pequeños agujeros de poste relacionados con la presencia de una mesa (Pecci, 2009b).

En el futuro sería interesante investigar espacios destinados al consumo de los alimentos, como los triclinia u otras áreas de consumo de alimentos de época romana, tardoantigua o medieval.

Quizás podamos considerar como parte de esta fase del ciclo de vida de los alimentos también su venta. En este caso habría que analizar los residuos en los pavimentos y bancos de las tabernas, o los espacios de los mercados de las diferentes épocas, como el trabajo realizado por Dahlin y otros autores (2007) en el área maya.

Al igual que para las cerámicas, se pueden analizar los espacios de consumo ritual de los alimentos y, sobre todo, los espacios de las ofrendas de alimentos a los dioses, que pueden ser públicos o privados. Ejemplos importantes son los estudios de espacios rituales de yacimientos mesoamericanos, donde existen altares y banquetas encima de los cuales 

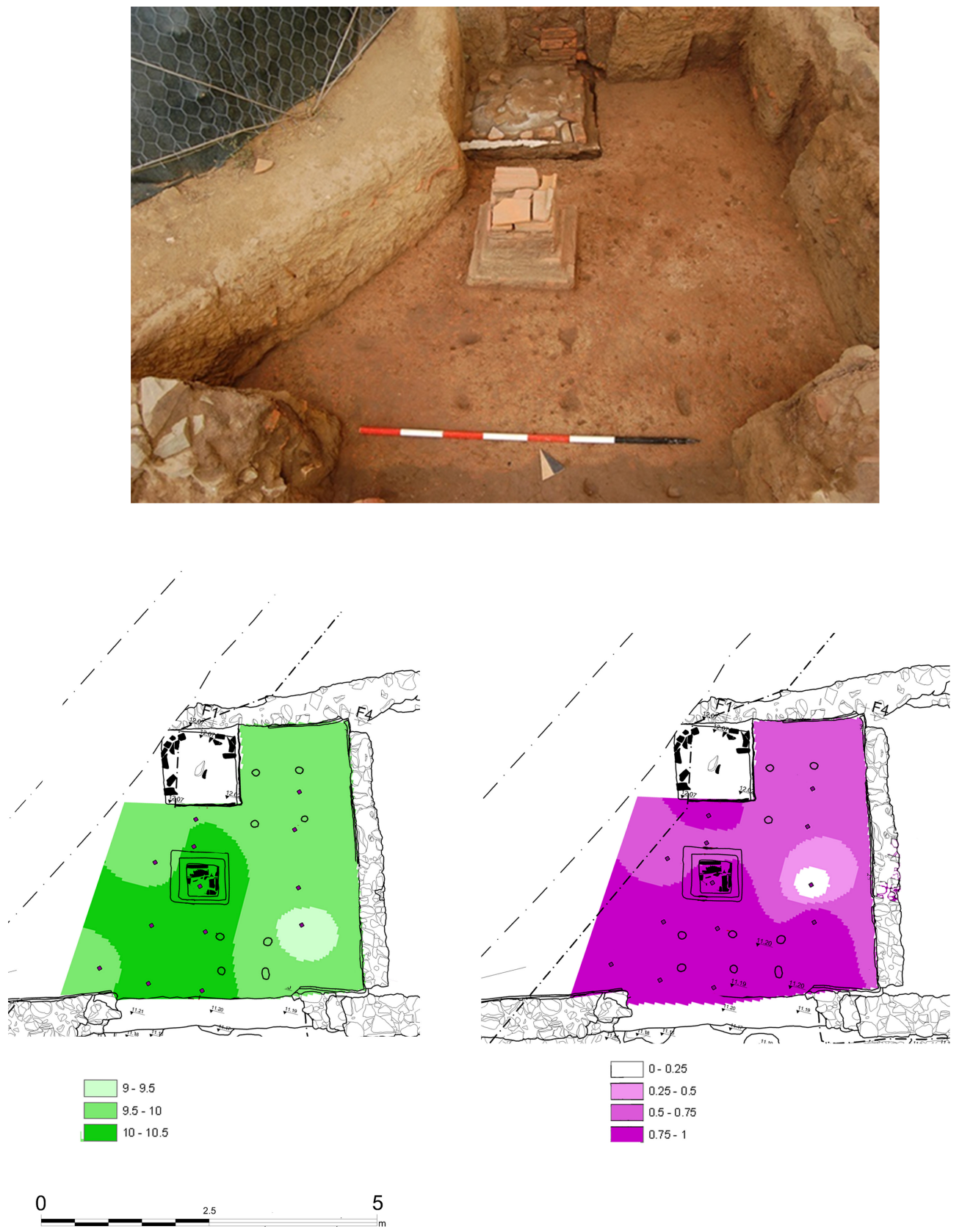

Figura 9. Altar doméstico hallado en la villa romana de Massaciuccoli y mapa de distribución de residuos protéicos (verde) y de ácidos grasos (rosa) obtenidos aplicando spot tests desarrollados por Barba (2007) en las muestras del altar y del pavimento. 
se depositaban ofrendas de alimentos a los dioses, se quemaba incienso o se derramaba sangre frente a las imágenes de las deidades (Barba et al., 1996). Sin embargo, existe un gran potencial de aplicación de análisis de espacios rituales en el área del Mediterráneo. En los altares públicos y privados griegos y romanos debería ser posible encontrar las trazas de sangre de los animales sacrificados, así como de los alimentos ofrendados y del incienso. Solo se ha probado su aplicación en un pequeño altar doméstico hallado en una villa romana en Massaciuccoli (Italia) (Pecci y Cau, 2012) (fig. 9).

\subsection{Desechos de alimentos}

En la mayoría de los casos, los alimentos no se desechan porque se consumen. Si se consideran desechos de alimentos solo los restos de comida y no los de la preparación de los alimentos, no se dispondrá de muchos materiales arqueológicos para el análisis químico. Pueden ser considerados desechos de alimentos, las heces, que se encuentran en letrinas, cloacas, desagües o estructuras de finalidad similar. Su análisis proporciona datos significativos sobre los alimentos consumidos, principalmente si se realizan estudios botánicos (es posible hallar semillas de higos, vid, etc.); sin embargo, su análisis, desde el punto de vista químico, no es imprescindible. Aun así, es posible reconocer los marcadores de las heces humanas, como ha demostrado, entre otros, el trabajo realizado por Bull y otros autores en el ágora de Atenas (Bull et al., 2003).

La presencia de heces se ha identificado químicamente también en algunos pozos para agua reutilizados como vertederos en el siglo XIII hallados durante las excavaciones de Via dei Castellani, en Florencia, tanto en la tierra del relleno como en algunas cerámicas que se contaminaron al estar en contacto con ella (Buonincontri et al., 2007, 2017).

Un aspecto interesante en el estudio de esta fase del ciclo de vida de los alimentos es el análisis de recipientes cerámicos o estructuras para verificar la recolección de desechos corporales como orina y heces para su reaprovechamiento, por ejemplo, para el encurtido de pieles y teñidos textiles.

\section{Conclusión}

Los resultados expuestos hasta aquí muestran el amplio espectro del análisis de residuos aplicado a materiales arqueológicos en relación con el ciclo de vida de los alimentos. Asimismo, revelan las amplias posibilidades todavía no explotadas. Es posible ampliar muchas de las líneas que aquí se han propuesto, desde la investigación del ciclo completo de la vida de los alimentos en un yacimiento concreto o en diferentes yacimientos de la misma época, con el fin de incrementar el conocimiento de la sociedad que allí vivía y detectar similitudes y diferencias en el aprovisionamiento, producción, preparación y 
consumo de los alimentos. Solo así se podrán comprender los diversos aspectos constitutivos de las sociedades: diferencias sociales, identidades y contactos culturales. Resultaría de interés, por ejemplo, verificar algunos de los temas propuestos por Reynolds y otros autores (2019) sobre la Antigüedad tardía a partir de los datos obtenidos hasta el momento. También será interesante concentrarse en el estudio de alimentos específicos. Los datos presentados evidencian que se podrían aislar algunos de ellos para explorar, por ejemplo, lo que podría definirse como la «biografía» del vino (García Vargas, 2019).

Para una mejor interpretación de los residuos absorbidos en los diferentes materiales arqueológicos es crucial combinar el estudio de esos materiales con la arqueología experimental y la etnoarqueología. La posibilidad de realizar trabajos etnoarqueológicos se ve afectada cada vez más por el abandono de técnicas tradicionales que ya no son rentables y la introducción de normas estrictas para el mantenimiento de la higiene. Esto ha provocado el cese de muchas actividades tradicionales, o al menos de las formas tradicionales de llevarlas a cabo. Nuestros primeros intentos de registro y muestreo de molinos para aceite o estructuras de producción de queso en Toscana fracasaron a causa de la transformación de todos los espacios productivos en ambientes estériles. En este sentido pensamos que es fundamental conocer y registrar las tradiciones mediterráneas milenarias que todavía se preservan.

La investigación interdisciplinar se revela como crucial y por ello toda intervención arqueológica debe prever, desde el inicio, muestreos de tipo arqueozoológico, arqueobotánico y de residuos químicos. Además, es fundamental complementar el estudio botánico tradicional de carbones y carporrestos con los análisis de microrrestos botánicos en el análisis de los pavimentos y de las cerámicas, facilitando una mejor comprensión de las prácticas alimenticias del pasado y del uso del espacio.

Es imprescindible combinar el estudio de residuos con el de los materiales donde los encontramos. Esto responde a la necesidad de conocer la proveniencia de estos materiales, como en el caso de las ánforas o de las cerámicas de cocina, para entender mejor la relación entre la proveniencia y su contenido (por ejemplo, Cau et al., 2018; Pecci y Cau, 2014b).

En el futuro será interesante indagar más a fondo las relaciones entre materiales inorgánicos y orgánicos, para comprender algunos aspectos tecnológicos que pueden proporcionar información sobre la absorción de los residuos en determinados materiales o la presencia de reacciones físico-químicas que implican la necesidad de tratamientos específicos de las superficies, como el caso de la pez aplicada en los dolia o el re-plastering de los enlucidos de los depósitos de las instalaciones productivas.

Asimismo, como se ha mencionado al inicio, se pueden estudiar residuos en cerámicas que no están directamente relacionadas con el ciclo alimenticio, como por ejemplo las lucernas, para entender cuál fue el combustible empleado; los ungüentarios de diferentes épocas, para averiguar las recetas de los ungüentos; los pebeteros, para identificar qué incienso era quemado, o las pipas, para confirmar su función como tales, o residuos sólidos, como aglutinantes, colas usadas en diferentes tipos de materiales, etc. Cada material conduce a seguir o abrir líneas de investigación exploradas y aportará, sin lugar a duda, importante información histórico-arqueológica. 
A ello se suma uno de los últimos avances en el estudio de residuos: la datación por radiocarbono, dado que los residuos orgánicos son, por su naturaleza, ricos en carbono (Casanova et al., 2020). Este hecho permitirá datar el uso de las cerámicas encontradas fuera de su contexto original y quizás, en el futuro, la datación de estructuras talladas en la roca, como los palmenti italianos o hispánicos.

\section{Agradecimientos}

Agradezco a los editores de Pyrenae, G. Ripoll, J. Nadal y M. Á. Cau, proponerme el reto de este artículo y sus observaciones. A los colegas que han dirigido y participado en los proyectos mencionados en el texto que me han impulsado a realizar análisis y/o han compartido inquietudes y horas de trabajo. A F. Inserra, S. Mileto y Ch. Valdambrini por compartir años de trabajo de laboratorio. Este trabajo se ha realizado en el marco del ERAAUB (2017SGR1043) (Comissionat per a Universitats i Recerca del DIUE de la Generalitat de Catalunya) y del proyecto I+D RACAMed (HAR2017-84242-P) que co-dirigo con P. Reynolds. A todos ellos mi agradecimiento y reconocimiento sincero. Cualquier omisión o malinterpretación es responsabilidad mía.

\section{Bibliografía}

ACCARDO, S., 2000, Villae romane nel Ager Bruttius, «L'Erma» di Bretschneider, Roma.

ALEXANDRE-BIDON, D., 2005, Une archéologie du goût. Céramique et consommation, Moyen Âge-Temps modernes, Editions Picard, París.

ALLEVATO, E., BUONINCONTRI, M., PECCI, A., CAU ONTIVEROS, M. Á., VAIRO, M., YONEDA, M., DE SIMONE, G. F., ANGELELLI, C., MATSUYAMA, S., TAKEUCHI, K. y DI PASQUALE, G., 2012, The cultural landscape en Campania (southern Italy) before 472 AD Vesuvius eruption: archaeoenvironmental data, Journal of Archaeological Science 39, 2, 399-406.

ALONSO, N., COLOMINAS, L., FONT, L., GARCÍA, LL., LIVARDA, A., PECCI, A., PORTILLO, M., VALENZUELA, S. y VERDÚN, E., 2019, Mostrejant la cuina: identificació bioarqueològica de les pràctiques culinàries, V Reunió Oikos de Bioarqueologia, UAB, Bellaterra, 18.

AROBBA, D., BULGARELLI, F., CAMIN, F., CARAMIELLO, R., LARCHER, R. Y MARTINELLI, L., 2014, Palaeobotanical, chemical and physical investigation of the content of an ancient wine amphora from the northern Tyrrhenian sea in Italy, Journal of Archaeological Science 45, 1, 226-233.

AUGENTI, A., 2019, I magazzini di Classe, Antiquité Tardive 27, 159-176.

BARBA, L., 1986, La química en el estudio de áreas de actividad, en L. MANZANILLA (ed.), Unidades habitacionales mesoamericanas y sus áreas de actividad, UNAM, México, 21-39.

BARBA, L., 2007, Chemical Residues in LimePlastered Archaeological Floors, Geoarchaeology: An International Journal 22, 4, 439-452. 
BARBA, L. y BELLO, G., 1978, Análisis de fosfatos en el piso de una casa habitada actualmente, Notas Antropológicas 1, 24, UNAM, México, 188-193.

BARBA, L., RODRÍGUEZ, R. y CÓRDOBA, J. L., 1991, Manual de técnicas microquímicas de campo para la arqueología, UNAM, México.

BARBA, L., ORTIZ, A., LINK, K., LÓPEZ LUJÁN, L. y LAZOS, L., 1996, Chemical Analisis of residues in floors and the reconstruction of ritual activities al Templo Mayor, Mexico, en M. V. ORNA (ed.), Archeological Chemistry. Organic, Inorganic, and Biochemical Analysis, American Chemical Society, Washington DC, 139-156.

BARBA, L., ORTIZ, A. y PECCI, A., 2014, Los residuos químicos. Indicadores arqueológicos para entender la producción, preparación, consumo y almacenamiento de alimentos en Mesoamérica, Anales de Antropología 48, 1, 201-239.

BARNARD, H., DOOLEY, A. N., ARESHIAN, G., GASPARYAN, B. y FAULL, K. F., 2011, Chemical evidence for wine production around $4000 \mathrm{BCE}$ in the Late Chalcolithic near eastern highlands, Journal of Archaeological Science 38, 977-984.

BARTON, H. J. y TORRENCE, R., 2015, Cooking up recipes for ancient starch: Assessing current methodologies and looking to the future, Journal of Archaeological Science 56, 194-201.

BEN JERBANIA, I., 2013, Observations sur les amphores de tradition punique d'après une nouvelle découverte près de Tunis, Antiquités Africaines 49, 179-197.

BERNAL-CASASOLA, D., 2015, What contents do we characterise in Roman Amphorae? Methodological and archaeological thoughts on a trending topic, Simposium Internacional Archaeoanalytics, en C. OLIVEIRA, R. MORAIS y Á. MORILLO (eds.), Archaeoanalythics, NPrint, Esposende, 61-83.

BERNAL-CASASOLA, D., 2019, Actividades haliéuticas en Hispania. De la pesca al garum, en E. SÁNCHEZ y M. BUSTAMANTE (eds.), Arqueología Romana en la Península Ibérica, Universidad de Granada - EUG Granada, 645-660.
BERNAL-CASASOLA, D. y VARGAS, J. M., 2019, El Testaccio haliéutico de Gades, en D. BERNAL-CASASOLA, J. M. VARGAS GIRÓN y M. LARA MEDINA (eds.), 7 metros de la Historia de Cádiz. Arqueología en El Olivillo y en el Colegio Mayor Universitario, UCA, Cádiz, 237-327.

BERNAL-CASASOLA, D., DÍAZ RODRÍGUEZ, J. J., LAVADO FLORIDO, M. L. Y GARCÍA GIMÉNEZ, R., 2019a, De la producción de ánforas Ovoide 1 gaditanas: aportaciones del alfar de Verinsur, en E. GARCÍA VARGAS, R. R. DE ALMEIDA, H. GONZÁLEZ CESTEROS y A. M. SÁEZ ROMERO (eds.), The Ovoid Amphorae in the Central and Western Mediterranean. Between the last two centuries of the Republic and the early days of the Roman Empire, Roman and Late Antique Mediterranean Pottery 13, Archaeopress, Oxford, 191-212.

BERNAL-CASASOLA, D., PECCI, A. y SÁEZ, A. M., $2019 b$, First residue analysis in Baetican Ovoid Amphorae, en E. GARCÍA VARGAS, R. R. DE ALMEIDA, H. GONZÁLEZ CESTEROS y A. M. SÁEZ ROMERO (eds.), The Ovoid Amphorae in the Central and Western Mediterranean. Between the last two centuries of the Republic and the early days of the Roman Empire, Roman and Late Antique Mediterranean Pottery 13, Archaeopress, Oxford 391-402.

BERNAL-CASASOLA, D., COTTICA, D. GARCÍA VARGAS, E., TONIOLO, L., SAEZ, A., BUSTAMANTE, M., CAPPELLETTO, E., PECCI, A., EXPÓSITO, J. A., LARA, M., DÍAZ J. J., VARGAS, J. M., MARLASCA, R. y RODRÍGUEZ, C. G., 2020, Ánforas, dolios y cerámica de la Bottega del Garvm $(\mathrm{I} 12,8)$ de Pompeya: reflexiones funcionales y socio-económicas, en M. OSANNA y L. TONIOLO (eds.), Fecisti Cretaria. Dal frammento al contesto: studi sul vasellame ceramico del territorio vesuviano, «L'Erma» di Bretschneider, Roma, 211-225.

BERNAL-CASASOLA, D., BONIFAY, M., LEICH, V. y PECCI, A. (eds.), en prensa, Roman Amphora Contents Interactive and Interdisciplinary Conference RAIIC, Cadiz (Spain) (5-7/10/2015), Archaeopress, Oxford.

BESHERER, K. y BEAUDRY, M. (eds.), 2015, Archaeology of Food. An Encyclopedia, Rowman \& Littlefield, Lanham. 
BONIFAY, M., 2004, Études sur la céramique romaine tardive d'Afrique, BAR Int. Series 1301, Archaeopress, Oxford.

BONIFAY, M., BOTTE, E., CAPELLI, C., CONTINO, A., DJAOUI, D., PANELLA, C. y TCHERNIA, A., 2015, Nouvelles hypothèses sur l'origine et le contenu des amphores africaines Ostia LIX et XXIII, Antiquités Africaines 51, 189-210.

BRILLAT-SAVARIN, A., 1869, Fisiología del gusto ó Meditaciones de gastronomía trascendental: obra teórica, histórica y á la orden del día dedicada á los gastrónomos parisienses, traducción del conde de Rodalquilar, Librería de Alfonso Durán, Madrid.

BRUN, J. P., 1993, La discrimination entre les installations oléicoles et vinicoles, M.C. AMOURETTI y J. P. BRUN (eds.), La production du vin et de l'huile en Mediterranée. Ecole Francaise d'Athènes, Atenas, 512-537.

BRUN, J. P.,2003, Le vin et l'huile dans la Méditerranée antique, Editions Errance, París.

BRUN, J. P., 2004, Archéologie du vin et de l'huile dans l'Empire romain, Editions Errance, París.

BULL, D., ELHMMALI, D., ROBERTS, D. L. y EVERSHED, R. P., 2003, The application of steroidal biomarkers to track the abandonment of a Roman wastewater course at the Agora (Athens, Greece), Archaeometry 45, 1, 143-161.

BUONINCONTRI, M. P., CORBINO, C. A., DI PASQUALE, G., DONNINI, D., MORI SECCI, M., PECCI, A., PIGNATTELLI, S., SALVINI, L. y TERZANI, M., 2007, Approccio integrato allo studio dell'alimentazione e dell'ambiente a Firenze nel XIII secolo: risultati preliminari, en R. FRANCOVICH, F. CANTINI, C. CIANFERONI y E. SCAMPOLI (eds.), Firenze prima degli Uffizi, All'Insegna del Giglio, Florencia, 662-681.

BUONINCONTRI, M., PECCI, A., DI PASQUALE, G., RICCI, P. y LUBRITTO, C., 2017, Multiproxy approach to the study of Medieval food habits in Tuscany (central Italy), Archaeological and Anthropological Sciences 9, 4, 653-671.

CARRERAS MONFORT, C., 2000, Economía de la Britannia romana: la importación de alimentos, Instrumenta 8, Universitat de Barcelona, Barcelona.
CASANOVA, E., KNOWLES, T., BAYLISS, A., DUNNE, J., BARA SKI, M., DENAIRE, A., LEFRANC, P., DI LERNIA, S., ROFFET-SALQUE, M., SMYTH, J., BARCLAY, A., GILLARD, T., CLASSEN, E., COLES, B., ILETT, M., JEUNESSE, C., KRUEGER, M., MARCINIAK, A., MINNITT, S., ROTUNNO, R., VAN DE VELDE, P., VAN WIJK, I., COTTON, J., DAYKIN, A. y EVERSHED, R. P., 2020, Accurate compound-specific 14C dating of archaeological pottery vessels, Nature 580, 506-523.

CAU ONTIVEROS, M. Á., MARTÍNEZ FARRERAS, V., PECCI, A., MAS FLORIT, C. y FANTUZZI, L., 2018, Archaeometric analysis for provenance and content of Roman amphorae from the site of Sa Mesquida (Mallorca, Spain), Mediterranean Archaeology and Archaeometry 18, 2, 87-105.

CHARTERS, S., EVERSHED, R. P., GOAD, L. J., LEYDEN, A., BLINKHORN, P. W. y DENHAM, V., 1993, Quantification and distribution of lipid in archaeological ceramics: implications for sampling potsherds for organic residue analysis and the classification of vessel use, Archaeometry 35, 2, 211-223.

CHARTERS, S., EVERSHED, R. P., QUYE, A., BLINKHORN, P. W. y REEVES, V., 1997, Simulation experiments for determining the use of ancient pottery vessels: the behaviour of epicuticular leaf wax during boiling of a leafy vegetable, Journal of Archaeological Science 27, 1-27.

COLOMBINI, M. P., GIACHI, G., MODUGNO, F. y RIBECHINI, E., 2005, Characterisation of organic residues in pottery vessels of the Roman age from Antinoe (Egypt), Microchemical Journal 79, 83-90.

CONDAMIN, J., FORMENTI, F., METAIS, M. O., MICHEL, M. y BOND, P., 1976, The application of Gas Chromatography to the tracing of oil in ancient anphorae, Archaeometry 18, 2, 195-201.

CONTINO, A. y CAPELLI, C. 2013, Amphores Tripolitaines anciennes ou amphores Africaines anciennes ?, Antiquités Africaines 49, 199-208.

COOK, S. R., FULFORD, M., CLARKE, A. y PEARSON, C., 2003, Soil geochemical analyses as an indication of metal working at the excavation of a house in the Roman City of Silchester (UK), Journal de Physique IV France 107, 319-321. 
COOK, S. R., FULFORD, M. y CLARKE, A., 2005, Soil geochemistry and detection of early Roman precious metal and copper alloy working at the Roman town of Calleva Atrebatum (Silchester, Hants), Journal of Archaeological Science 32, 805-12.

COPLEY, M. S., BERSTAN, R., DUDD, S. N., DOCHERTY, G., MUCKHERJEE, A. J., STRAKER, V., PAYNE, S. y EVERSHED, R. P., 2003, Direct chemical evidence for widespread dairying in prehistoric Britain, PNAS 100, 4, 1524-1529.

COPLEY, M. S., BLAND, H. A., ROSE, P., HORTON, M. y EVERSHED R. P., 2005, Gas chromatographic, mass spectrometric and stable carbon isotopic investigations of organic residues of plant oils and animal fats, employed as illuminants in archaeological lamps from Egypt, Analyst 130, 6, 860-871.

CORREA-ASCENCIO, M. y EVERSHED, R. P., 2014, High throughput screening of organic residues in archaeological potsherds using direct acidified methanol extraction, Analythical Methods 6, 1330-1340.

CRAIG, O. E., FORSTER, M., ANDERSEN, S. H., KOCH, E., CROMBE, P., MILNER, N. J., STERN, B., BAILEY, G. N. y HERON, C. P., 2007, Molecular and isotopic demonstration of the processing of aquatic products in northern European prehistoric pottery, Archaeometry 49, 1, 135-152.

CRAMP, L. J. E., EVERSHED, R. P. y ECKARDT, H., 2011 , What was a mortarium used for? Organic residues and cultural change in Iron Age and Roman Britain, Antiquity 85, 330, 1339-1352.

DAHLIN, B., JENSEN, C., TERRY, R., WRIGHT, D. y BEACH, T., 2007, In search of an ancient Maya market, Latin American Antiquity 18, 4, 363-384.

DAHLIN, B., BLAIR, D., BEACH, T., MORIARTY, M. y TERRY, R., 2010, The Dirt on Food: Ancient Feasts and Markets Among the Lowland Maya, en J. STALLER y M. CARRASCO (eds.) PreColumbian Foodways. Interdisciplinary Approaches to Food, Culture, and Markets in Ancient Mesoamerica, Springer, Nueva York, 191-232.
DI PASQUALE, G., PECCI, A., RICCIARDI, S., DI FALCO, G., BUONINCONTRI, M. y LUBRITTO, C., 2006, Dal paesaggio alla funzione delle strutture: primi risultati delle analisi archeobotaniche e chimiche a Miranduolo, en R. FRANCOVICH y M. VALENTI (eds.), Atti del IV Congresso Nazionale di Archeologia Medievale, All'Insegna del Giglio, Florencia, 41-46.

DRIEU, L., RAGEOT, M., WALES, N., STERN, B., LUNDY, J., ZERRER, M., GAFFNEY, I., BONDETTI, M., SPITERI, C., THOMAS-OATES, J. y CRAIG, O., 2020, Is it possible to identify ancient wine production using biomolecular approaches?, STAR 6, 16-29.

DUDD, S. y EVERSHED, R. P., 1998, Direct demonstration of milk as an element of archaeological economies, Science 282, 1478-1481.

DUNNE, J., EVERSHED, R. P., SALQUE, M., CRAMP, L., BRUNI, S., RYAN, K., BIAGETTI, S. y DI LERNIA, S., 2012, First dairying in green Saharan Africa in the fifth millennium BC, Nature 486, 7403, 390-394.

DUNNE, J., GRILLO, K. M., CASANOVA, E. y EVERSHED, R. P., 2019, Pastoralist Foodways Recorded in Organic Residues from Pottery Vessels of Modern Communities in Samburu, Kenya, Journal of Archaeological Method and Theory 26, 619-642.

DUNNE, J., CHAPMAN, A., BLINKHORN, P. y EVERSHED, R. P., 2020, Fit for purpose? Organic residue analysis and vessel specialisation: The perfectly utilitarian medieval pottery assemblage from West Cotton, Raunds, Journal of Archaeological Science 120, 105-178.

EGÜEZ, N., ZERBONI, A. y BIAGETTI, S., 2018, Microstratigraphic analysis on a modern central Saharan pastoral campsite. Ovicaprine pellets and stabling floors as ethnographic and archaeological referential data, Quaternary International 483, 180-193.

EMPEREUR, J. Y. y PICON, M., 1989, Les régions de production d'amphores impériales en Mediterranée Orientale, in Amphores romaines et histoire économique : dix ans de recherches, Mélanges de l'École Française de Rome 114, Roma, 223-248. 
ESTEVE, X., MOLIST, N., RIPOLL, G., PECCI, A., FARRE HUGUET, J. y PEÑA CERVANTES, Y., 2018, Medieval Rock-cut wine presses and cellars in Olerdolá (Barcelona). A recent discovery, European Association of Archaeologists/EAA/Annual Meeting, Book of Abstracts, Barcelona (5-9 September 2018), Barcelona, 501.

ÉTIENNE, R. y MAYET, F., 2000, Le vin hispanique, De Boccard, París.

EVERSHED, R. P., 1993, Biomolecular archaeology and lipids, World Archaeology 25, 74-93.

EVERSHED, R. P., 2008, Organic residues in archaeology: the archaeological biomarker revolution, Archaeometry 50, 6, 895-924.

EVERSHED, R. P., VAN BERGEN, P., PEAKMAN, T., LEIGH-FIRBANK, E., HORTON, M., EDWARDS, D., BIDDLE, M., KJØLBYE-BIDDLE, B. Y ROWLEY-CONWY, P., 1997, Archaeological Frankincence, Nature 390, 667-668.

EVERSHED, R. P., DUDD, S., ANDERSON STOJANOVIC, V. R. y GEBHARD, E., 2003, New chemical evidence for the use of Combed ware pottery vessels as beehives in ancient greece, Journal of Archaeological Science 30, 1-12.

EVERSHED, R. P., PAYNE, S., SHERRATT, A. G., COPLEY, M. S., COOLIDGE, J., UREM-KOTSU, D., KOTSAKIS, K., OZDOGAN, M., OZDOGAN, A. E., NIEUWENHUYSE, O., AKKERMANS, P., BAILEY, D., ANDEESCU, R. R., CAMPBELL, S., FARID, S., HODDER, I., YALMAN, N., OZBASARAN, M., BICAKCI, E., GARFINKEL, Y., LEVY, T. y BURTON, M. M., 2008, Earliest date for milk use in the Near East and Southeastern Europe linked to cattle herding, Nature 455, 7212, 528-531.

BURTON, M. M., 2008, Earliest date for milk use in the Near East and Southeastern Europe linked to cattle herding, Nature 455, 7212 , 528-531.

FERNÁNDEZ, F., TERRY, R., INOMATA, T. y EBERL, M., 2002, An ethnoarchaeological study of chemical residues in the floors and soils of Q'eqchi' Maya houses at Las Pozas, Guatemala, Geoarchaeology 17, 6, 487-519.
FOURNET, J.-L. y PIERI, D., 2008, Les dipinti amphoriques d'Antinoopolis, in Antinoupolis I, Florencia, 175-216.

FRÈRE, D. y GARNIER, N., 2017, Dairy Product and Wine in Funerary Rituals: The Case of a Hellenistic Etruscan Tomb, Journal of Historical Archaeology and Anthropological Sciences 1, 6, 222-227.

GANZAROLLI, G., ALEXANDER, M., CHAVARRIA, A. y CRAIG, O., 2018, Direct evidence from lipid residue analysis for the routine consumption of millet in Early Medieval Italy, Journal of Archaeological Science 96, 124-130.

GARCÍA ÁLVAREZ-BUSTO, A., LACA, A. y FERNÁNDEZ GONZÁLEZ, A., 2019, Revealing the Monastic Kitchen: Chemical Analysis of the Soil Inside the Monastery of Cornellana (North-West Spain): Soil inside the monastery of Cornellana (north-west Spain), Archaeometry 61, 1, 145-160.

GARCÍA VARGAS, E., 2012, Producciones anfóricas tardorrepublicanas y tempranoaugusteas del valle del Guadalquivir, in Cerámicas Hispanorromanas II, Cádiz.

GARCÍA VARGAS, E., 2019, La arqueología de la producción: Pasado, presente ¿y futuro?, en E. SÁNCHEZ y M. BUSTAMANTE (eds.), Arqueología Romana en la Península Ibérica, Universidad de Granada - EUG Granada, 515-528.

GARCÍA VARGAS, E., BERNAL-CASASOLA, D., PALACIOS, V. M., ROLDÁN, A., RODRÍGUEZ ALCÁNTARA, A. y SÁNCHEZ GARCÍA, J., 2014, Confectio Gari Pompeiani. Procedimiento experimental para la elaboración de salsas de pescado romanas, SPAL 23, 65-82.

GARNIER, N., 2007, Analyse de résidus organiques conservés dans des amphores: un état de la question, en M. BONIFAY y J. C. TRÉGLIA (eds.), LRCW2 Late Roman Coarse Wares, Cooking Wares and Amphorae in the Mediterranean, Archaeopress, Oxford, 39-58.

GARNIER, N., 2014, Analyse chimique des sauces et des conserves de poissons : un état de la question, en E. BOTTE (ed.), Fish $\theta$ Ships. Production and commerce of salsamenta during Antiquity, Editions Errance, París, 17-36. 
GARNIER, N., 2015, Méthodologies d'analyse chimique organique en archéologie, en R. MORAIS, Á. MORILLO CERDAN y C. OLIVEIRA (eds.), ArchaeoAnalytics: Chromatography and DNA analysis in archaeology, Esposende, 13-39.

GARNIER, N. y DUBUIS, B., 2019, Looking for ancient wine as gift for the Prince of Lavau (5th c. BC), en P. STOCKHAMMER y J. FRIESKNOBLACH (eds.), Was tranken die frühen Kelten?, Sidestone Press, Leiden, 193-201.

GARNIER, N. y VALAMOTI, S. M., 2016, Prehistoric wine-making at Dikili Tash (Northern Greece): Integrating residue analysis and archaeobotany, Journal of Archaeological Science 74, 195-206.

GARNIER, N., ROLANDO, C., MUNK HØTJE, J. y TOKARSKI, C., 2009, Analysis of archaeological triacylglycerols by high resolution nanoESI, FTICR MS and IRMPD MS/MS: Application to 5th century BC-4th century AD oil lamps from Olbia (Ukraine), International Journal of Mass Spectrometry 284, 47-56.

GARNIER, N., SILVINO, T. y BERNAL-CASASOLA, D., 2011, The identification of the content of amphorae: oils, salsamenta and pitch, en French Society for the Study of Archaeological Ceramics from Gallia, Proceedings of the Congress SFECAG (Arles, June 2011), Arles, 397-416.

GARNIER, N., BERNAL-CASASOLA, D., DRIARD, C. y PINTO, I. V., 2019, Looking for ancient fish products through invisible biomolecular residues in the Roman production vats from the Atlantic coast, Journal of Maritime Archaeology 13, 285-328.

GARNIER, N. y PECCI, A., en prensa, Amphorae and residue analysis, en D. BERNAL-CASASOLA, M. BONIFAY, V. LEICH V. y A. PECCI (eds.), Roman Amphora Contents Interactive and Interdisciplinary Conference - RAIIC, Cadiz (Spain) (5-7/10/2015), Archaeopress, Oxford.

GRAINGER, S., 2012, Garum, liquamen and muria: a new approach to the problem of definition, en E. BOTTE (ed.), Fish $\theta$ Ships. Production and commerce of salsamenta during Antiquity, Editions Errance, París.
GUASCH-JANÉ, M. R., IBERNO GÓMEZ, M., ANDRÉS-LACUEVA, C., JÁUREGUI, O. y LAMUELA-RAVENTÓS, R. M., 2004, Liquid chromatography with mass spectrometry in Tandem mode applied for the identification of wine markers in residues from ancient Egyptian vessels, Analytical Chemistry 76, 6, 1672-1677.

HAMILAKIS, Y., 2013, Archaeology of senses, Cambridge University Press, Cambridge.

HAMMANN, S., CRAMP, L. J. E., WHITTLE, M. y EVERSHED, R. P., 2018, Cholesterol degradation in archaeological pottery mediated by fired clay and fatty acid pro-oxidants, Tetrahedron Letters 59 4401-4404.

HAMMANN, S. y CRAMP, L. J. E., 2018, Towards the detection of dietary cereal processing through absorbed lipid biomarkers in archaeological pottery, Journal of Archaeological Science 93, 74-81.

HANSEL, F. A. y EVERSHED, R. P., 2009, Formation of dihydroxy acids from Z-monounsaturated alkenoic acids and their use as biomarkers for the processing of marine commodities in archaeological pottery vessels, Tetrahedron Letters 50, 40, 5562-5564.

HENDERSON, P., 2009, Sulphur dioxide. Science behind this anti-microbial, anti-oxidant wine additive. PW-Practical Winery and Vineyard, 1-6.

HERON, C., EVERSHED, R. P. y GOAD, L. J., 1991, Effects of migration of soil lipids on organic residues associated with buried potsherds, Journal of Archaeological Science 18, 641-659.

HERON, C., SHODA, S., BREU BARCONS, A., CZEBRESZUK, J., ELEY, Y., GORTON, M., KIRLEIS, W., KNEISEL, J., LUCQUIN, A., MÜLLER, J., NISHIDA, Y., SON, J. y CRAIG, O. E., 2016, First molecular and isotopic evidence of millet processing in prehistoric pottery vessels, Scientific Reports 6, 38767.

INSERRA, F. y PECCI, A., 2011, A Medieval tavern: chemical analyses of floors at San Genesio (Central Italy), en I. TURBANTI MEMMI (ed.), Advances in Archaeometry. Proceedings of the 37th International Symposium on Archaeometry, 13th-16th May, 2008, Siena, Springer, Berlin, 459-464. 
INSERRA, F., PECCI, A., CAU ONTIVEROS, M. Á. y ROIG BUXÓ, J., 2015, Organic residues analysis of Late Antique pottery from Plaça Major-Horts de Can Torras (Castellar del Vallés, Catalonia, Spain), Periodico di Mineralogia 84, 1, 123-138.

JACOBSON, J. L., 2006, Introduction to wine laboratory practices and procedures, Springer, Nueva York.

JORNET, R., BELARTE, M. C., ASENSIO, D., MORER, J., SANMARTÍ, J. y NOGUERA, J., en prensa, Intervencions al jaciment ibèric de Coll del Moro de Gandesa (Terra Alta) entre 2014 i 2018, Tribuna d'Arqueologia 2018-2019, Generalitat de Catalunya, Departament de Cultura, Barcelona.

KNUDSON, K. y FRINK, L., 2010,

Ethnoarchaeological analysis of Arctic fish processing: chemical characterization of soils on Nelson Island, Alaska, Journal of Archaeological Science 37, 769-783.

LEMAÎTRE, S., 2000, Les importations d'amphores de Méditerranée orientale à Lyon au IIIe siècle ap. J.-C., Rei Cretariae Fautorum Acta 36, 467-476.

LÉVI-STRAUSS, C., 2008 [1969], The Culinary Triangle, en C. COUNIHAN y P. VAN ESTERIK (eds.), Food and Culture: A Reader, Routledge, Nueva York, 40-47.

LANCELOTTI, C., PECCI, A. y ZURRO, D., 2017, Anthropic activity markers: archaeology and ethnoarchaeology, Environmental Archaeology 22, 4, 339-342.

LÓPEZ VARELA, S., ORTIZ, A. y PECCI, A., 2006, Ethnoarchaeological Study of chemical Residues in a "living" household in Mexico, en

H. KARS y E. BURKE (eds.), Proceedings of the 33 rd International Symposium on Archaeometry, 22-26 april 2002, Amsterdam, Geoarchaeological and Bioarchaeological Studies 3, Vrije Universiteit, Amsterdam, 19-22.

MANZANILLA, L. y BARBA, L., 1990, The Study of Activities in Classic Households, Two Case Studies from Cobá and Teotihuacan, Ancient Mesoamerica 1, 1, 41-49.

MANNONI, T. y GIANNICHEDDA, E., 1996, Archeologia della produzione, Einaudi, Turín.
MANZANO, E., CANTARERO, S., GARCÍA, A., ADROHER, A. y VÍLCHEZ, J. L., 2016, A multianalytical approach applied to the archaeological residues in Iberian glasses. Earliest evidences on the consumption of fermented beverages in votive rituals, Microchemical Journal 129, 286-292.

MCGOVERN, P., 2004, L'archeologo e l'uva, Carocci, Roma.

MCGOVERN, P. E., LULEY, B., ROVIRA, N., MIRZOIAN, A., CALLAHAN, M. P., SMITH, K., HALL, G. R., DAVIDSON, T. Y HENKIN, J. M., 2013, Beginning of viniculture in France, PNAS $110,25,10147-10152$.

MCGOVERN, P., JALABADZE, M., BATIUK, S., CALLAHAN, M. P., SMITH, K., HALL, G., KVAVADZE, E., MAGHRADZE, D., RUSISHVILI, N., BOUBY, L., FAILLA, O., COLA, L., MARIANI, L., BOARETTO, E., BACILIERI, R., THIS, P., WALES, N. y LORDKIPANIDZE, L., 2017, Early Neolithic wine of Georgia in the South Caucasus, PNAS 114, 48, 10309-10318

MIDDLETON, W., 2004, Identifying Chemical Activity Residues on Prehistoric House Floors: a Methodology and Rationale for Multi-Elemental Characterization of a Mild Acid Extract of Anthropogenic Sediments, Archaeometry 46, 1, 47-65.

MIDDLETON, W., BARBA, L., PECCI, A., BURTON, J. H., ORTIZ, A., SALVINI, L. Y RODRIGUEZ SUÁREZ, R., 2010, The Study of Archaeological Floors: Methodological Proposal for the Analysis of Anthropogenic Residues by Spot Tests, ICP-OES, and GC-MS, Journal of Archaeological Method and Theory 17, 183-208.

MIDDLETON, W. y PRICE, D., 1996, Identification of Activity Areas by Multi-element Characterization of Sediments from Modern and Archaeological House Floors Using Inductively Coupled Plasma-atomic Emission Spectroscopy, Journal of Archaeological Science 23, 673-687.

MILLS, J. S. y WHITE, R., 1987, The organic chemistry of Museums objects, Routledge, Londres.

MONTANARI, M., 1989, Alimentazione e cultura nel Medioevo, Laterza, Bari. 
MOTTRAM, H. R., DUDD, S. N., LAWRENCE, G. J., STOTT, A. W. y EVERSHED, R. P., 1999, New chromatographic, mass spectrometric and stable isotope approaches to the classification of degraded animal fats preserved in archaeological pottery, Journal of Chromatography A 833, 209-221.

OONK, S., SLOMP, C. P. y HUSIMAN, D. J., 2009, Geochemsity as an Aid in Archaeological Prospection and Site Interpretation: Current Issues and Research Directions, Archaeological Prospection $16,1,35-51$.

ORTIZ, A. y BARBA, L., 1993, La química en el estudio de áreas de actividad, en L. MANZANILLA (ed.), Anatomía de un conjunto residencial teotihuacano en Oztoyahualco, UNAM, México, $617-$ 660.

ORTIZ, A., PECCI, A. y BARBA, L., 2018, Las actividades del centro de barrio de Teopancazco a partir de sus residuos químicos, en L. MANZANILLA (ed.) Teopancazco como centro de barrio multiétnico de Teotihuacan. los sectores funcionales y el intercambio a larga distancia. Primera parte. Teopancazco y sus sectores Funcionales, UNAM, México, 83-156.

PANELLA, C. y RIZZO, G., 2014, Ostia VI. Le anfore di Ostia e i commerci mediterranei, Studi Miscellanei 38, "L'Erma» di Bretschneider, Roma.

PARNELL, J. J., TERRY, R. Y NELSON, Z., 2002, Soil Chemical Analysis Applied as an Interpretive Tool for Ancient Human Activities in Piedras Negras, Guatemala, Journal of Archaeological Science $29,379-404$.

PECCI, A., 2004, Le analisi funzionali di alcuni livelli di vita bassomedievali, en G. BIANCHI (ed.) Castello di Donoratico. I risultati delle prime campagne di scavo (2000-2004), Quaderni del Dipartimento di Archeologia e Storia delle Arti Sezione Archeologia, Università di Siena, Edizioni Insegna del Giglio, Florencia, 93-97.

PECCI, A., 2006, Rivestimenti organici nelle ceramiche medievali: un accorgimento tecnologico «invisibile»?, Archeologia Medievale 23, 517-523.
PECCI, A., 2007, Potenzialità delle analisi chimiche applicate all'archeologia dei consumi alimentari: un bilancio delle conoscenze, en A. CIACCI, P. RENDINI y A. ZIFFERERO (eds.), Archeologia della vite e del vino in Etruria, Ci.Vin, Siena, 123-131.

PECCI, A., 2009a, Analisi funzionali della ceramica e alimentazione medievale, Archeologia Medievale 36, 21-42.

PECCI, A., 2009b, Analisi chimiche delle superfici pavimentali: un contributo all'interpretazione funzionale degli spazi archeologici, en G. VOLPE y P. FAVIA (eds.), V Congresso Nazionale di Archeologia Medievale, All'Insegna del Giglio, Florencia, 105-110.

PECCI, A., 2010, Olio ed oli: le analisi dei residui organici nelle ceramiche, en G. BARBIERI,

A. CIACCI y A. ZIFFERERO (eds.), Eleiva, Oleum, Olio. Le origini dell'olivicoltura in Toscana: nuovi percorsi di ricerca tra archeologia, botanica e biologia molecolare, Editrice DonChisciotte, San Quirico d'Orcia, 213-228.

PECCI, A., 2013, Almost ten years of plasters residue analysis in Italy: activity areas and the function of structures, Periodico di Mineralogia 82, 3, 393-410

PECCI, A., 2016, Appendice. Analisi dei residui in tre dolia rinvenuti nella UT 88, en G. CORDIANO (ed.), Carta archeologica del litorale ionico aspromontano, Edizioni Ets, Pisa, 163-166.

PECCI, A., 2018, Analisi dei residui organici e anfore medievali, Archeologia Medievale 45, 275-280.

PECCI, A., 2019. Arqueología de la alimentación y análisis de residuos, en E. SÁNCHEZ y M. BUSTAMANTE (eds.), Arqueología Romana en la Península Ibérica, Universidad de Granada - EUG Granada, 543-554.

PECCI, A., en prensa $a$, La producció i el consum de vi a través de les anàlisis dels residus químics en materials arqueològics, Tribuna d'Arqueologia 2018-2019, Generalitat de Catalunya, Departament de Cultura, Barcelona. 
PECCI, A., en prensa $b$, L'analisi chimica dei pavimenti e dei contenitori per derrate della cosiddetta Casa delle anfore - UT 161, en A. ZIFFERERO (ed.), Marsiliana d'Albegna. Dagli Etruschi a Tommaso Corsini, Siena.

PECCI, A. y CAU ONTIVEROS, M. Á., 2010, Análisis de residuos orgánicos en ánforas. El problema de la resina y del aceite, en Estudios sobre el Monte Testaccio (Roma) V, Instrumenta 35, Universitat de Barcelona, Barcelona, 593-600.

PECCI, A. y CAU ONTIVEROS, M. Á., 2012, Risultati preliminari delle analisi dei pavimenti, en F. ANICHINI (ed.), Massaciuccoli Romana. La campagna di scavo 2011-2012. I dati della ricerca, Edizioni Nuova Cultura, Roma, 389-383.

PECCI, A. y CAU ONTIVEROS, M. Á., 2014a, Análisis de residuos orgánicos en algunas ánforas del Monte Testaccio, en Estudios sobre el Monte Testaccio (Roma) VI, Instrumenta 47, Universitat de Barcelona, Barcelona, 601-613.

PECCI, A. y CAU ONTIVEROS, M. Á., 2014b, Residue Analysis of Late Roman Cooking pots and Amphorae from Sa Mesquida (Mallorca, Balearic Islands), en N. POULOU-PAPADIMITRIOU, E. NODAROU y V. KILIKOGLOU (eds.), LRCW4 Late Roman Coarse Wares, Cooking Wares and Amphorae in the Mediterranean. Archaeology and archaeometry. The Mediterranean: a market without frontiers, Salonicco (7-10 April 2011), BAR Int. Series S2616, Oxford, 833-841.

PECCI, A. y CAU ONTIVEROS, M. Á., 2020, Appendix 1: Organic residue analysis of two wine dolia from the Vrina Plain, en D. HERNÁNDEZ y R. HODGES, Butrint 7, Beyond Butrint, Oxbow Books, Oxford, 181-182.

PECCI, A. y D'ANDRIA, F., 2014, Oil production in Roman times: residue analysis of the floors of an installation in Lecce (southern Italy), Journal of Archaeological Science 46, 363-371.

PECCI, A. y GIORGI, G., 2019, Le anfore, en D. BERNAL-CASASOLA y D. COTTICA (eds.), Scambi e commerci in area vesuviana. I dati delle anfore dai saggi stratigrafici I.E. (Impianto Elettrico) 1980-81 nel Foro di Pompei, Roman and Late Antique Mediterranean Pottery 14, Archaeopress, Oxford, 157-164.
PECCI, A., SALVINI, L., CIRELLI, E. y AUGENTI, A., 2010, Castor oil at Classe (Ravenna. Italy): residue analysis of some Late Roman amphorae coming from the port, en S. MENCHELLI, S. SANTORO, M. PASQUINUCCI Y G. GUIDUCCI (eds.), LRCW3. Late Roman Coarse Wares, Cooking Wares and Amphorae in the Mediterranean. Archaeology and Archaeometry, BAR Int. Series 2185, Archaeopress, Oxford, 617-622.

PECCI, A., CAU ONTIVEROS, M. Á. y GARNIER, N., 2013a, Identifying wine and oil production: analysis of residues from Roman and Late Antique plastered vats, Journal of Archaeological Science 40, 4491-4498.

PECCI, A., CAU ONTIVEROS, M. Á., VALDAMBRINI, C. e INSERRA, F., 2013b, Understanding residues of oil production: chemical analyses of floors in traditional mills, Journal of Archaeological Science 40, 883-893.

PECCI, A., GIORGI, G., SALVINI, L. y CAU ONTIVEROS, M. Á., 2013c, Identifying wine markers in ceramics and plasters with gas chromatography - mass spectrometry, Journal of Archaeological Science 40, 1, 109-115.

PECCI, A., DEGL'INNOCENTI, E., GIORGI, G., CAU ONTIVEROS, M.Á., CANTINI, F., SOLANES POTRONY, E., AÓS, C. y MIRIELLO, D., 2016a, Organic residue analysis of experimental, medieval, and post medieval glazed ceramics, Archaeological and Anthropological Sciences 8, 4, 879890.

PECCI, A., DI PASQUALE, G., CAMPOREALE, S., BUONINCONTRI, M., ALLEVATO, E. Y PAPI, E., 2016b, Preliminary analyses of amphorae and dolia from Thamusida (Morrocco), en R. JARREGA y P. BERNI (eds.), Amphorae ex Hispania. Paisajes de producción y de consumo, III Congreso Internacional de la SECAH - Ex Officina Hispana. Tarragona (10-13 dicembre 2014), ICAC -SECAH, Tarragona, 612-614.

PECCI, A., GABRIELI, R. S., INSERRA, F., CAU ONTIVEROS, M. Á. y WAKSMAN, S. Y., 2016c, Preliminary results of the organic residue analysis of 13th century cooking wares from a household in Frankish Paphos (Cyprus), STAR 1, 2, 99-105. 
PECCI, A., BARBA, L. y ORTIZ, A., 2017a, Chemical residues as anthropic activity markers. Ethnoarchaeology, Experimental Archaeology and Archaeology of food production and consumption, Environmental Archaeology 22, 4, 343-353.

PECCI, A., BARBA, L. y ORTIZ, A., 2017b, Los residuos químicos de la producción de pulque. Etnoarqueometría y arqueología experimental, Anales de Antropología 51, 39-55.

PECCI, A., CLARKE, J., THOMAS, M., MUSLIN, J., VAN DER GRAAFF, I., TONIOLO, L., MIRIELLO, D., CRISCI, G. M., BUONINCONTRI, M. y DI PASQUALE, G., 2017c, Use and reuse of amphorae. Wine residues in Dressel 2-4 amphorae from Oplontis Villa B (Torre Annunziata, Italy), Journal of Archaeological Science: Reports 12, 515-521.

PECCI, A., DOMÍNGUEZ-BELLA, S., BUONINCONTRI, M., MIRIELLO, D., DE LUCA, R., DI PASQUALE G., COTTICA D. y BERNALCASASOLA, D., 2018, Combining residue analysis of floors and ceramics for the study of activity areas at the Garum Shop at Pompeii, Archaeological and Anthropological Sciences 10, 485-502.

PECCI, A., BORGNA, A., MILETO, S., DALLA LONGA, E., BOSI, G., FLORENZANO, A., MERCURI, A. M., CORAZZA, S., MARCHESINI, M. y VIDALE, M., 2020a, Wine consumption in Bronze Age Italy: combining organic residue analysis, botanical data and ceramic variability, Journal of Archaeological Science 123, 105256.

PECCI, A., GARNIER, N. y WAKSMAN, S. Y., $2020 b$, Residue analysis of medieval amphorae from the Eastern Mediterranean, en S. Y. WAKSMAN (ed.), Multidisciplinary approaches to food and foodways in the medieval Eastern Mediterranean, MOM éditions, Lyon, 417-428.

PECCI, A., REYNOLDS, P., MILETO, S., VARGAS, J. M. y BERNAL-CASASOLA, D., en prensa, Production and transport of goods in the Roman period: residue analysis and wine derivatives in late Republican Baetican ovoid amphorae, Environmental Archaeology.

PEÑA CERVANTES, Y., 2010, Torcularia. La producción de vino y aceite en Hispania, Documenta 14, ICAC, Tarragona.
PEÑA CERVANTES, Y., 2019. Producción agropecuaria, en E. SÁNCHEZ y M. BUSTAMANTE (eds.), Arqueología Romana en la Península Ibérica, Universidad de Granada - EUG Granada, 615-643.

RAGEOT, M., MÖTSCH, A., SCHORER, B., WINKLER, D. B., SACCHETTI, F., CHAUME, B. Y CASA, P. D., et al. 2019, New Insights Into Early Celtic Consumption Practices: Organic Residue Analyses of Local and Imported Pottery From VixMont Lassois, PLoS ONE 14, 0218001.

REBER, E., DUDD, S., VAN DER MERWE, N. y EVERSHED, R. P., 2004, Direct detection of maize processing in archaeological pottery through compound-specific stable isotope analysis of n-dotriacontanol in absorbed organic residues, Antiquity 78, 301, 682-691.

REGERT, M., COLINART, S., DEGRAND, L. y DECAVALLAS, O., 2001, Chemical alteration and use of beeswax through time: accelerated ageing tests and analysis of archaeological samples from various environmental contexts, Archaeometry 43, 4, 549-569.

REGERT, M., 2011, Analytical strategies for discriminating archeological fatty substances from animal origin, Mass Spectrometry 30, 177-220.

REMOLÀ I VALLVERDÚ, J. A., 2000, Las ánforas tardo-antiguas en Tarraco (Hispania Tarraconensis), Instrumenta 7, Universitat de Barcelona, Barcelona.

REYNOLDS, P., 2010a, Hispania and the Roman Mediterranean, AD 100-700: Ceramics and Trade, Londres.

REYNOLDS, P., 2010b, Trade networks of the East, 3rd to 7th centuries: the view from Beirut and Butrint (fine wares, amphorae and kitchen wares), en S. MENCHELLI, S. SANTORO, M. PASQUINUCCI y G. GUIDUCCI (eds.), LRCW3. Late Roman Coarse Wares, Cooking Wares and Amphorae in the Mediterranean. Archaeology and Archaeometry, BAR Int. Series 2185, Archaeopress, Oxford, 89-114.

REYNOLDS, P., RIPOLL, G., MICHEL

D'ANNOVILLE, C. y DUGAST, F., 2019, 
L'alimentation dans l'Antiquité Tardive, Antiquité Tardive 27, 17-24.

REYNOLDS, P., en prensa, Amphorae of the Roman East, en M. BONIFAY, D. BERNALCASASOLA, V. LEICH y A. PECCI (eds.), Roman Amphora Contents Interactive and Interdisciplinary Conference - RAIIC, Cadiz (Spain) (5-7/10/2015).

RODRÍGUEZ ALCÁNTARA, Á., BERNALCASASOLA, D., GARCÍA VARGAS, E., ROLDÁN GÓMEZ, A. M. y PALACIOS V., 2020, Avances en la recuperación tecnológica del garum romano: pruebas de envejecimiento en ánforas, en D. BERNAL-CASASOLA, A. M. ROLDÁN y V. PALACIOS (eds.), Baelo Claudia y los secretos del Garum, Editorial UCA, Cádiz, 158-177.

ROFFET-SALQUE, M., DUNNE, J., ALTOFT, T., CASANOVA, E., CRAMP, L., SMYTH, J., WHELTON, H. y EVERSHED, R. P., 2017, From the inside out: Upscaling organic residue analyses of archaeological ceramics, Journal of Archaeological Science: Reports 16, 627-640.

ROFFET-SALQUE, M., REGERT, M., EVERSHED, R. P., OUTRAM, A. K., CRAMP, L. J. E., DECAVALLAS, O., DUNNE, J., GERBAULT, P., MILETO, S., MIRABAUD, S., PÄÄKKÖNEN, M., SMYTH, J., ŠOBERL, L., WHELTON, H. L., ALDAY-RUIZ, A., ASPLUND, H., BARTKOWIAK, M., BAYER-NIEMEIER, E., BELHOUCHET, L., BERNARDINI, F., BUDJA, M., COONEY, G., CUBAS, M., DANAHER, E. M., DINIZ, M., DOMBORÓCZKI, L., FABBRI, C., GONZÁLEZURQUIJO, J. E., GUILAINE, J., HACHI, S., HARTWELL, B. N., HOFMANN, D., HOHLE, I., IBÁÑEZ, J. J., KARUL, N., KHERBOUCHE, F., KIELY, J., KOTSAKIS, K., LUETH, F., MALLORY, J. P., MANEN, C., MARCINIAK, A., MAURICE-CHABARD, B., MC GONIGLE, M. A., MULAZZANI, S., ÖZDOG AN, M., PERI , O. S., PERI, S. R., PETRASCH, J., PÉTREQUIN, A. M., PÉTREQUIN, P., POENSGEN, U., JOSHUA POLLARD, C., POPLIN, F., RADI, G., STADLER, P., STÄUBLE, H., TASI , N., UREM-KOTSOU, D., VUKOVI , J. B., WALSH, F., WHITTLE, A., WOLFRAM, S., ZAPATA-PEÑA, L. Y ZOUGHLAMI, J., 2015, Widespread exploitation of the honeybee by early Neolithic farmers, Nature 527.

ROMANUS, K., BAETEN, J., POBLOME, J., ACCARDO, S., DEGRYSE, P., JACOBS, P., DE VOS, D. y WAELKENS, M., 2009, Wine and olive oil permeation in pitched and nonpitched ceramics: relation, with results from archaeological amphorae from Sagalassos, Turkey, Journal of Archaeological Science 36, 900-909.

RONDELLI, B., LANCELOTTI, C., MADELLA, M., PECCI, A., BALBO, A., RUIZ PEREZ, J., INSERRA, F., GADEKAR, C., CAU, M. A. y AJITHPRASAD, P., 2014, Anthropic activity markers and spatial variability: an ethnoarchaeological experiment in a domestic unit of Northern Gujarat (India), Journal of Archaeological Science 41, 482-492.

RÖSCH, M., 2005, Pollen analysis of the contents of excavated vessels, Vegetation History and Archaeobotan 14, 3, 179-188.

ROSE, A. H., 1993, Sulphur dioxide and other preservatives, Journal of Wine Research 4, 1, 43-47.

RUDOLPH, K., 2018, Taste and the ancient senses, Routledge, Nueva York-Londres.

RUSSELL, A., 2011, In the Middle of the Corrupting Sea: Cultural Encounters in Sicily and Sardinia between 1450-900 BC., Unpublished PhD Thesis, Department of Archaeology, College of Arts, University of Glasgow.

SALQUE, M., BOGUCKI, P. I., PYZEL, J., SOBKOWIAK-TABAKA, I., GRYGIEL, R., SZMYT, M. y EVERSHED, R. P., 2013, Earliest evidence for cheese making in the sixth millennium bc in northern Europe, Nature 493, 522-525.

SÁNCHEZ, A. y CAÑABATE, M. L., 1998, Indicadores químicos para la arqueología, Universidad de Jaén, Jaén.

SANGINETO, B., 1992, Il deposito di anfore di Trebisacce ed un recipiente per la Pix Bruttia, en F. COSTABILE (ed.), Polis ed Olympeion a Locri Epizefiri. Costituzione, economia e finanze di una città della Magna Grecia. Editio altera e traduzione delle tabelle locresi, Rubbettino, Catanzaro, 183-191. 
SALVINI, L., PECCI, A. y GIORGI, G., 2008, Cooking Activities during the Middle Ages: organic residues in ceramic vessels from the Sant'Antimo Church (Piombino - Central Italy), Journal of Mass Spectrometry 43, 108-115.

SCHIFFER, M., 1992, Technological Perspectives on Behavioral Change, University of Arizona Press, Tucson.

SCHIFFER, M., SKIBO, J., BOELKE, T., NEUPERT, M. y ARONSON, M., 1994, New perspectives on experimental archaeology: surface treatments and termal response of the clay cooking pot, American Antiquity 59, 2, 197-217.

SEMPERE, E., 1982, Rutas a los alfares, España Portugal, Barcelona.

SHILLITO, L.-M., 2017, Multivocality and multiproxy approaches to the use of space: lessons from 25 years of research at Çatalhöyük, Word Archaeology, 237-259.

SKYBO, J., 2013, Understanding Pottery Function, Springer, Heidelberg.

STERN, B., HERON, C., CORR, L., SERPICO, M. y BOURRIAU, J., 2003, Compositional variations in aged and heated Pistacia resin found in Late Bronze Age Canaanite amphorae and bowls from Amarna, Egypt, Archaeometry 45, 3, 457-469.

TCHERNIA, A., 2011, Les Romains et le commerce, Centre Jean Bérard, Nápoles.

TONIOLO, L. y PECCI, A., 2020, Il ciclo di vita del vino. Casi studio dall'area vesuviana, en J. P. BRUN, N. GARNIER y G. OLCESE (eds.),
Making Wine in Western-Mediterranean, Panel 3.5, Propylaeum, Heidelberg, 131-142.

WELLS, E. C., TERRY, R. E., PARNELL, J. J., HARDIN, P. J., JACKSON, M. W. y HOUSTON, S. D., 2000, Chemical analyses of ancient anthrosols in residential areas at Piedras Negras, Guatemala, Journal of Archaeological Science 27, 449-462.

WELLS, E. C., PRATT, S. M., FOX, G., SIEGEL, P., DUNNING, P. y MURPHY, A., 2017, Plantation Soilscapes: Initial and Cumulative Impacts of Colonial Agriculture in Antigua, West Indies, Environmental Archaeology 23-35.

VALDAMBRINI, C., PECCI, A. y SALVINI, L., 2006, Ceramiche da mensa e da dispensa da alcuni siti della provincia di Grosseto: rapporto contenuto/contenitore, Convegno Internazionale della ceramica, La ceramica da fuoco e da dispensa nel basso medioevo e nella prima età moderna (secoli XI$X V I)$, Savona, 26-27 maggio 2006, All'Insegna del Giglio, Florencia, 120-128.

WOODWORTH, M., BERNAL, D., BONIFAY, M., DE VOS, D., GARNIER, N., KEAY, S., PECCI, A., POBLOME, J., POLLARD, M., RICHEZ, F. Y WILSON, A., 2015, The content of African Keay 25/Africana 3 amphorae: initial results, en C. OLIVEIRA, R. MORAIS y Á. MORILLO (eds.), Archaeoanalythics, NPrint, Esposende, 42-57.

ZIFFERERO, A., PECCI, A., PEPI, A., SANCHIRICO, C. y SANTORO, E., 2011, Marsiliana d'Albegna: nuovi dati dall'area suburbana, en G. FACCHIN y M. MILLETTI, Materiali per Populonia 10, Edizioni ETS, Pisa, 289-320. 